Progress Report, December 2010: Improved Site Characterization And Storage Prediction Through Stochastic Inversion Of Time-Lapse Geophysical And Geochemical Data

A. Ramirez, W. Mcnab, S. Carle, Y. Hao, D. White, J. Johnson

January 3, 2011 
This document was prepared as an account of work sponsored by an agency of the United States government. Neither the United States government nor Lawrence Livermore National Security, LLC, nor any of their employees makes any warranty, expressed or implied, or assumes any legal liability or responsibility for the accuracy, completeness, or usefulness of any information, apparatus, product, or process disclosed, or represents that its use would not infringe privately owned rights. Reference herein to any specific commercial product, process, or service by trade name, trademark, manufacturer, or otherwise does not necessarily constitute or imply its endorsement, recommendation, or favoring by the United States government or Lawrence Livermore National Security, LLC. The views and opinions of authors expressed herein do not necessarily state or reflect those of the United States government or Lawrence Livermore National Security, LLC, and shall not be used for advertising or product endorsement purposes.

This work performed under the auspices of the U.S. Department of Energy by Lawrence Livermore National Laboratory under Contract DE-AC52-07NA27344. 
Theme 3B: Storage Monitoring Methods

Task 3b.11: Forward-Tuned Stochastic Modeling

\title{
Progress Report, December 2010: Improved Site Characterization And Storage Prediction Through Stochastic Inversion Of Time-Lapse Geophysical And Geochemical Data
}

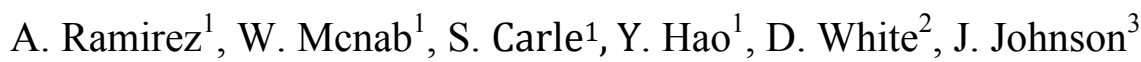 \\ 1-Lawrence Livermore National Laboratory \\ 2-Geological Survey of Canada \\ 3-Schlumberger Doll Research \\ LLNL-TR-464614
}

\begin{abstract}
Over the last project six months, our project activities have concentrated on three areas: performing a stochastic inversion of pattern 16 seismic data to deduce reservoir permeability, 2) development of the geochemical inversion strategy and implementation of associated software, and 3) completing the software implementation of TProGS and the geostatistical analysis that provides the information needed when using the software to produce realizations of the Midale reservoir. The report partially the following deliverables:

D2: Model development: MCMC tool (synthetic fluid chemistry data); deliverable completed.

D4: Model development/verification: MCMC tool (TProGS, field seismic/chemistry data) work product; deliverable requirements partially fulfilled.

D5: Field-based single-pattern simulations work product; deliverable requirements partially fulfilled.
\end{abstract}

This work has been performed under the auspices of the U.S. Department of Energy by Lawrence Livermore National Laboratory under Contract DE-AC52-07NA27344

\section{Introduction}

When completed, our completed stochastic inversion tool will explicitly integrate reactive transport modeling, facies-based geostatistical methods, and a novel stochastic inversion technique to optimize agreement between observed and predicted storage performance. Such optimization will be accomplished through stepwise refinement of: 1) the reservoir model — principally its permeability magnitude and heterogeneity - and 2) geochemical parameters - primarily key mineral volume fractions and kinetic data. We 
anticipate that these refinements will facilitate significantly improved history matching and forward modeling of $\mathrm{CO}_{2}$ storage. Our tool uses the Markov Chain Monte Carlo (MCMC) methodology.

Deliverable D1, previously submitted as a report titled "Development of a Stochastic Inversion Tool To Optimize Agreement Between The Observed And Predicted Seismic Response To $\mathrm{CO}_{2}$ Injection/Migration in the Weyburn-Midale Project" (Ramirez et al., 2009), described the stochastic inversion approach that will identify reservoir models that optimize agreement between the observed and predicted seismic response. The software that implements this approach has been completed, tested, and used to process seismic data from pattern 16. A previously submitted report titled "Model verification: synthetic single pattern simulations using seismic reflection data", Ramirez et al. 2010, partially fulfilled deliverable D3 by summarizing verification activities that evaluate the performance of the seismic software and its ability to recover reservoir model permeabilities using synthetic seismic reflection data. A future progress report will similarly describe summarizing verification activities of the geochemical inversion software, thereby completing deliverable D3.

This document includes a chapter that shows and discusses permeability models produced by seismic inversion that used seismic data from pattern 16 in Phase 1A. It partially fulfills deliverable D5: Field-based single-pattern simulations work product. The D5 work product is supposed to summarize the results of applying NUFT/MCMC to refine the reservoir model and geochemical parameters by optimizing observation/prediction agreement for the seismic/geochemical response to $\mathrm{CO} 2$ injection/migration within a single pattern of Phase $1 \mathrm{~A} / 1 \mathrm{~B}$. A future progress report will show inversion results for the same pattern using geochemical data, thereby completing deliverable D5.

This document also contains a chapter that fulfills deliverable D2: Model development: MCMC tool (synthetic fluid chemistry data). The chapter will summarize model development activities required to facilitate application of NUFT/MCMC to optimize agreement between the observed and predicted geochemical response to $\mathrm{CO} 2$ injection/migration.

Lastly, this document also contains a chapter that partially fulfills deliverable D4: Model development/verification: MCMC tool (TProGS, field seismic/chemistry data) work product. This work product is supposed to summarize model development activities required for (1) application of TProGS to Weyburn, (2) use of TProGS within the MCMC tool, and (3) application of the MCMC tool to address field seismic and geochemical data. The chapter included here fulfills requirements 1 and 2. Requirement 3 will be addressed in a future progress report. 


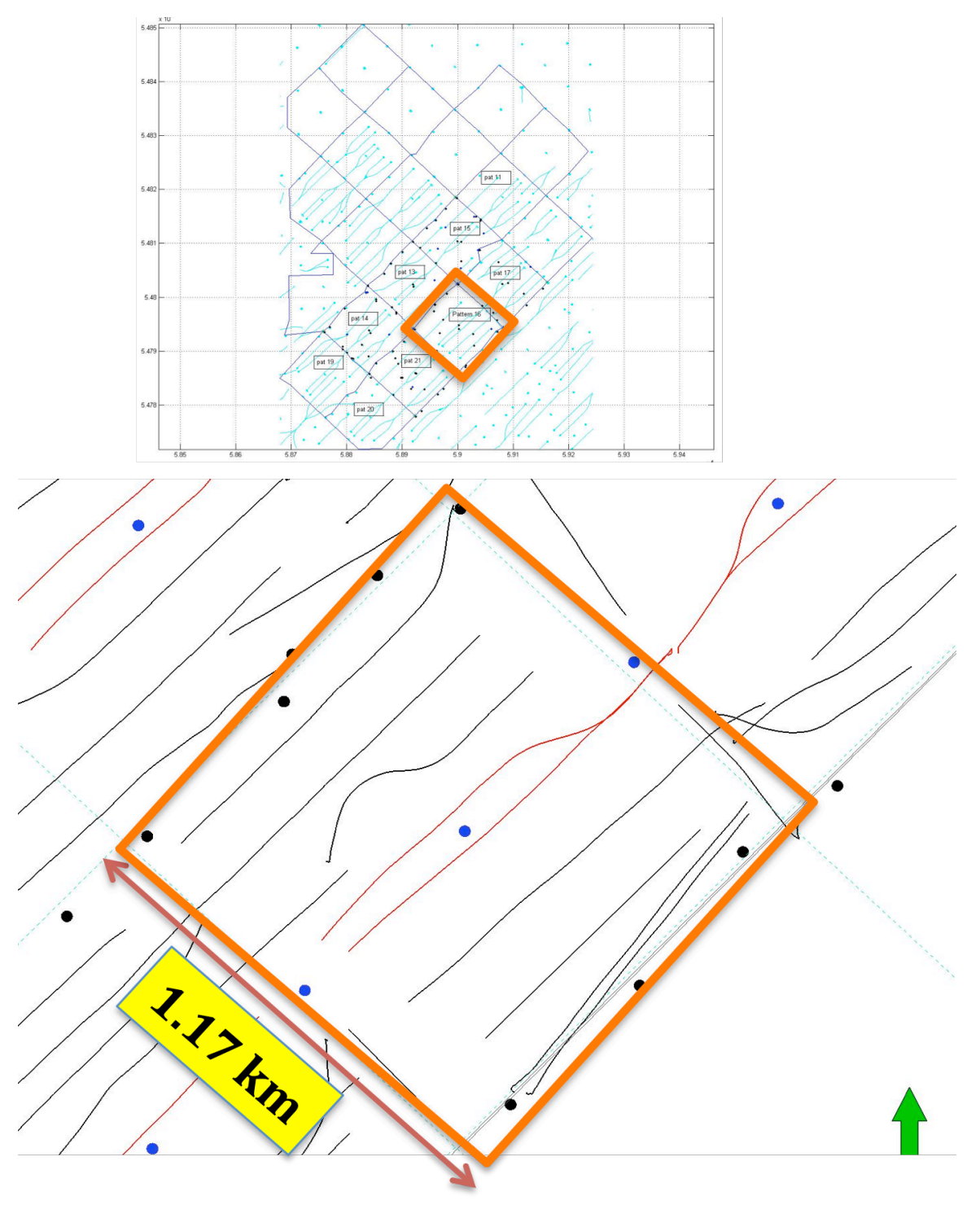

Figure 1.1. The orange square shows the location of the pattern where seismic data used by our inversion was collected. This pattern is within the Phase 1A area of the WeyburnMidale reservoir. Borehole layout provided by Barbara Dietiker (Geological Survey of Canada). The red lines indicate the location of the $\mathrm{CO}_{2}$ injector, the blue circles represent the WAG injectors and the black lines and circles represent the oil producers.

\section{Chapter 1: Preliminary Seismic Results, Pattern 16, Phase 1A}

We have performed several stochastic inversions using seismic data from pattern 16, Phase 1A area. Here we present the results of one of those inversions. Initial results suggested the need for improving the method used to generate predicted seismic waveforms. This chapter will also describe three recent modifications made to the seismic algorithm that are aimed at increasing the accuracy of the predicted 
waveforms. This chapter will also describe the path forward regarding seismic inversion.

Figure 1.1 shows details of the reservoir region considered for this inversion. The region consisted of pattern 16, Phase $1 \mathrm{~A}$ and included a $\mathrm{CO}_{2}$ injector, oil producers and water injectors. The size of the region is $1.17 \mathrm{~km}$ by 1.17 kilometers by $1.46 \mathrm{~km}$ (depth).

The initial seismic algorithm implementation (Ramirez et al., 2009) used a Ricker wavelet to simulate the effects of the source that generated the seismic energy. We are now using a wavelet inverted from seismic data shown in Figure 1.2 (wavelet provided by D. White, Geological Survey of Canada, personal communication, 2010). This wavelet has minimum phase (energy is front loaded), as expected of dynamite explosions. The waveforms produced using the field-based wavelet are more accurate than those produced with the Ricker wavelet because the former better represents the properties of the seismic source.
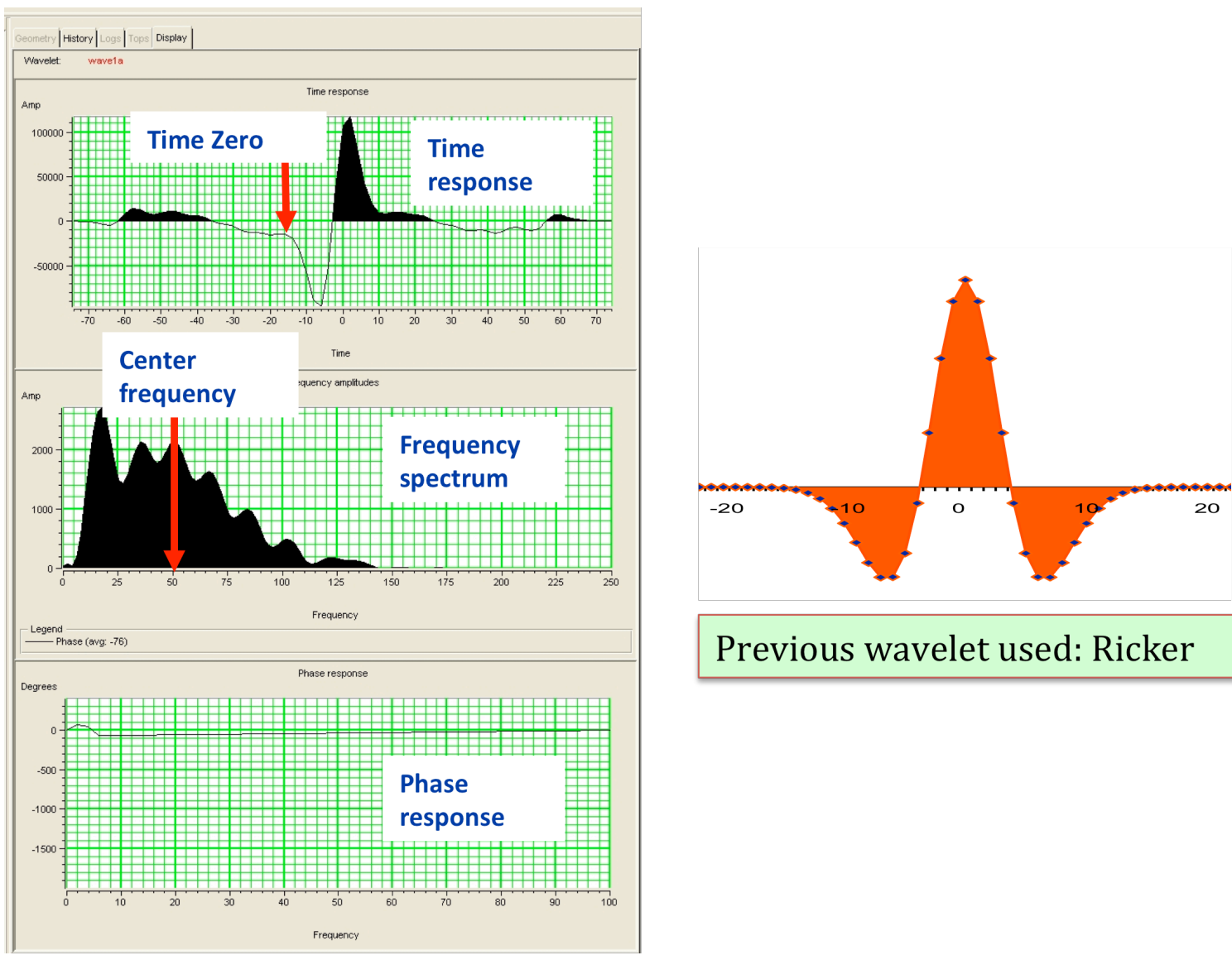

Previous wavelet used: Ricker

Figure 1.2. Left side shows the field-derived wavelet now used to represent the properties of the source when calculating the seismograms. In our previous work, we used a Ricker wavelet (right side). Field-derived wavelet provided by D. White (Geological Survey of Canada).

We have also re-engineered how the predicted and seismic waveforms are aligned and compared. In our seismic application, we need to compare predicted and observed 
waveforms in order to calculate the misfit between the two. This requires that the predicted waveform be shifted in time by an amount determined by cross-correlation with the observed waveform. The initial implementation cross-correlated the full length of the predicted and observed waveforms. We are now only using the part of the waveforms that corresponds to the Ratcliffe peak to do the cross-correlation and determine the time shift. Also, we increased the time-sampling rate of the predicted waveforms to improve the accuracy of the cross-correlation used for waveform alignment.

The third change involves the bulk modulus used by the seismic calculations. Initially, we used core measurements of seismic moduli measured in the laboratory (Brown, 2002). The graphs on the left side of Figure 1.3 compare two sets of predicted (red curves) and observed (blue curves) waveforms; observed waveforms were measured in 1999, before $\mathrm{CO}_{2}$ injection started. Time is increasing from left to right on the graphs. Note that the predicted waveforms (red curves) over-predict the amplitude of the peak associated with the top of the Midale Vuggy.

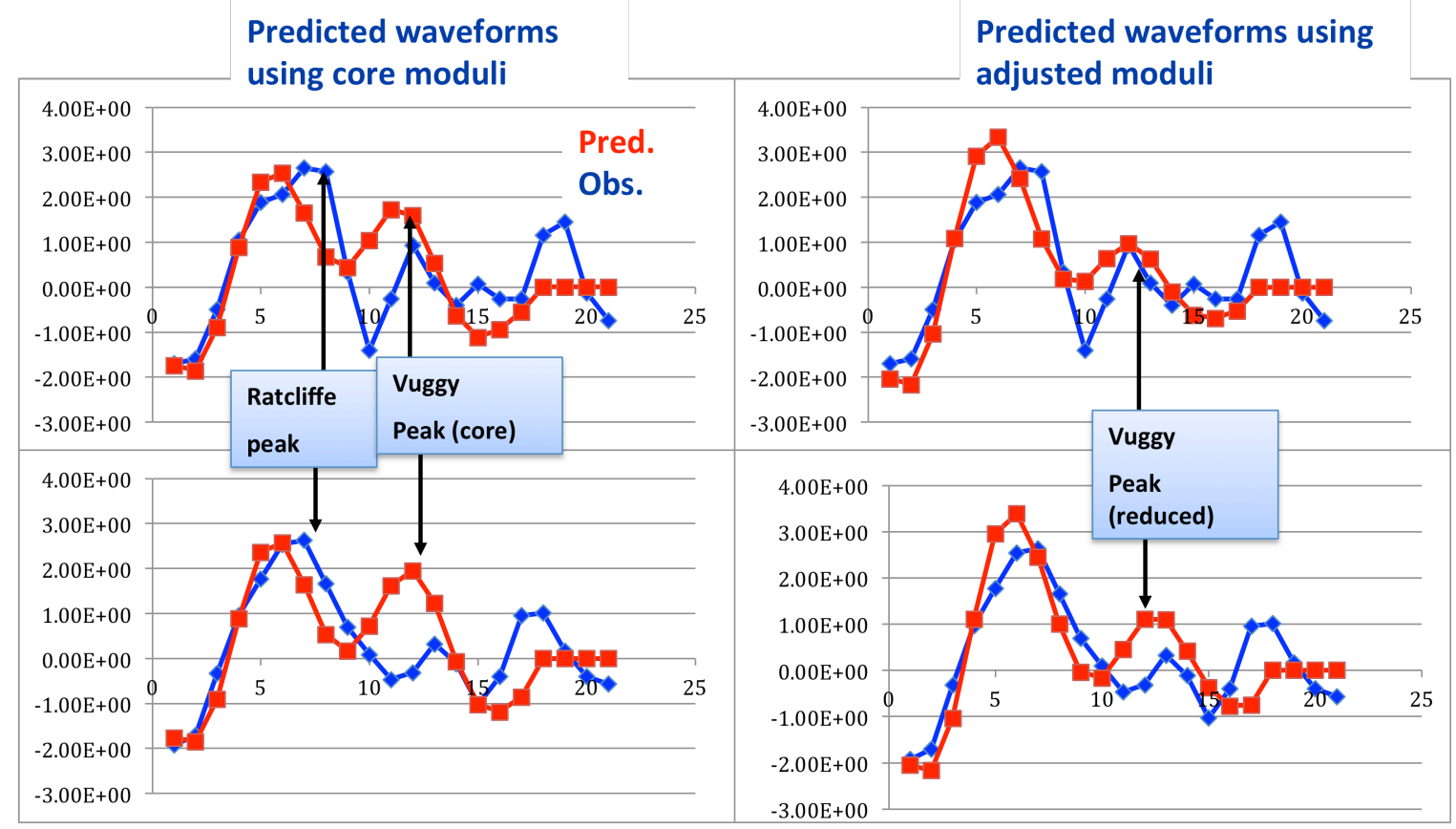

Figure 1.3. Comparison of predicted (red) and observed (blue) waveforms using seismic moduli measured in the laboratory (left side) and after adjustment by trial and error (right side).

We suggest that the Vuggy peak over-predictions indicate that the core-measured moduli over-estimate the strength of the in situ rock because the core measurements do not include the effects of large fractures. To test this hypothesis, we manually adjusted the Vuggy bulk modulus by trial and error, and calculated the root mean squared (RMS) misfit between the observed and predicted waveforms. The RMS misfit reached a minimum when the Vuggy's bulk modulus was reduced by $42 \%$. The right graphs in Figure 3 show examples of waveforms using the reduced bulk modulus. Note the lower 
amplitude of the predicted Vuggy peak. This result suggests that the in situ Vuggy limestone is softer than the Vuggy core, probably due to the presence of fractures not sampled by the core. We believe that additional work is needed to obtain better estimates of reservoir seismic properties, as we will discuss in a subsequent section of this chapter.

We then used the adjusted Vuggy modulus to obtain the stochastic inversion results described later in this chapter.

The inversion approach we followed consisted of the following steps; for additional details of our MCMC stochastic inversion technique, see Ramirez et al. $(2009,2010)$. First, we generated random realizations of porosity/permeability. In this document, we call these realizations reservoir models. These models honored geostatistical trends in Cenovus' model (provided by Barbara Dietiker, Geol. Survey of Canada) calibrated against several decades of production data; these trends identified the statistical distributions of porosity and permeability in the reservoir layer, and the correlation between porosity and permeability. The realizations consist of porosity and permeability fields that vary spatially within each layer while honoring the porosity/permeability trends embedded in Cenovus' calibrated model (Figures 3 and 4, Ramirez et al., 2010). The porosity fields proposed honor the bimodal distribution shown by the histogram in Figure 3, left side, Ramirez et al., 2010. The permeability fields honor the distribution shown on the right side of Figure 3. The porosity/permeability distributions also honor the cross-correlation trends shown in Figure 4, Ramirez et al., 2010. Each realization also honored lithology designations and layer boundaries in Cenovus' model.

The next step consisted of running the flow simulator while honoring the $\mathrm{CO}_{2}$ injection and fluid production rates used in the field; this step predicted various reservoir parameters such as fluid densities, $\mathrm{CO}_{2}$ saturation and pore pressure for each realization. We then predicted seismic velocities throughout the model using the calculated reservoir parameters and Gassmann's equation. The velocity model was then used to compute seismic reflectivities and zero-offset, 1D seismograms. The algorithm then compared the predicted and observed seismograms, calculated the likelihood function (proportional to data misfit), and used the likelihood value to decide whether to accept or reject the current realization. Our MCMC stochastic inversion technique will find those permeability models that best fit the seismic data and the "prior" constraints (lithology boundaries and geostatistical trends).

\section{Results}

We will now discuss permeability models produced by the stochastic inversion. It is important to recognize that these results are preliminary due to factors that we describe later in this chapter.

The flow simulation assumed that water was injected for 2 years, and that $\mathrm{CO}_{2}$ injection started after 0.7 years of water injection. The top row of images in Figure 5 show the $\mathrm{CO}_{2}$ saturations calculated by the flow simulator after 1.3 years of $\mathrm{CO}_{2}$ injection. The seismic data used for the inversion was collected circa December 2001. 


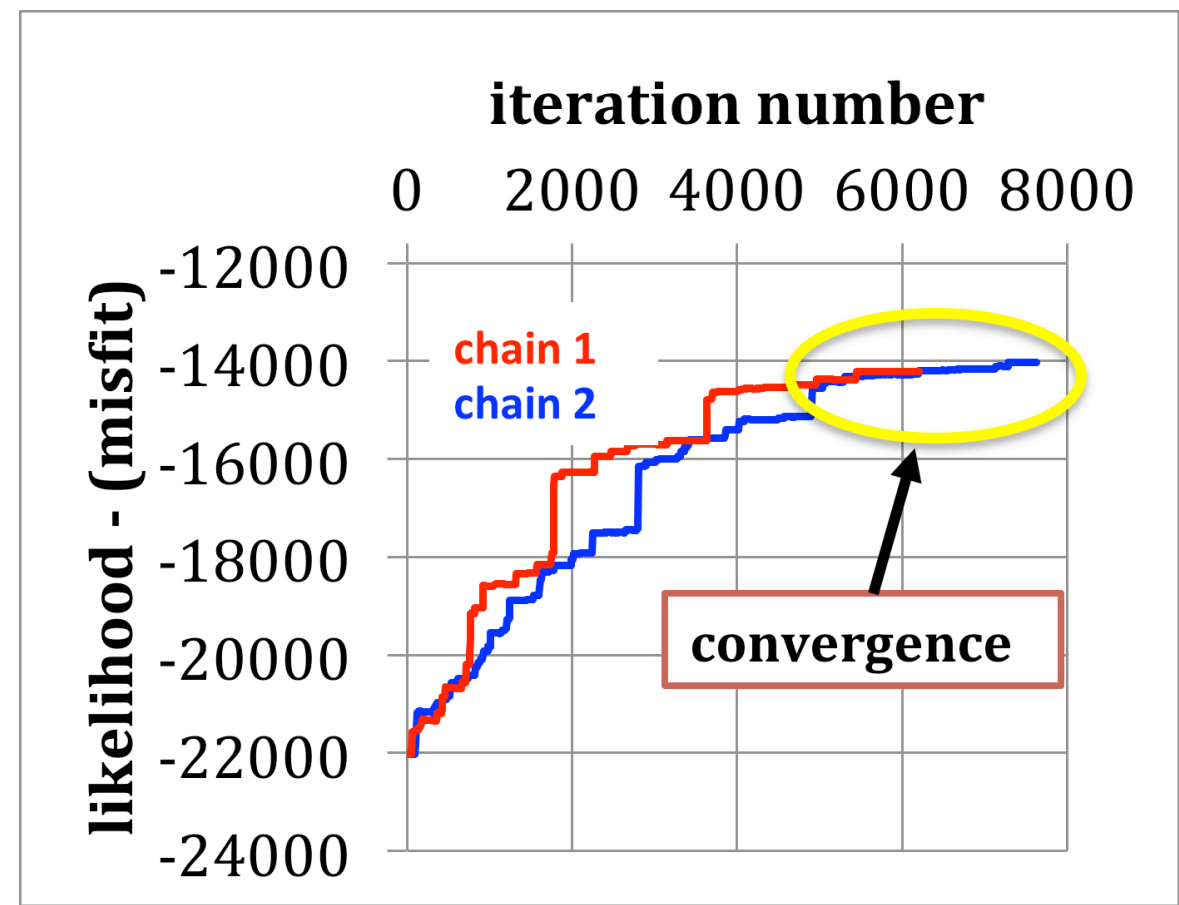

Figure 1.4. Plot of the likelihood value as a function of iteration. Note that the likelihood value is a measure of the similarity between the predicted and observed seismic waveforms; more positive values indicate that the predicted waveforms are increasingly similar to the observations. Note that a stable value is achieved after about 5000 iterations.

Figure 1.4 shows a plot of the likelihood value as a function of iteration for the seismic inversion run we will show later. The likelihood value is proportional to the data misfit, i.e., the sum of the differences between the observed and predicted waveforms (see Ramirez et al., 2009 for details). The plot shows that the there are two Markov chains; each chains starts at a different point of solution space. The plot shows that likelihood is improving and that both chains reach a similar and stable value after about 5000 iterations. This means that both Markov chains are sampling models that fit the data equally well and that any further improvement in the likelihood is likely to be small or negligible. In statistical parlance, this means that the seismic inversion has converged after 5000 iterations and that the Markov chains are now sampling from the posterior distribution, the collection of models that contains the solution to our stochastic inversion problem. In other words, we can use models produced after iteration 5000 to obtain a statistically reliable estimate of the spatially-variable reservoir permeabilities.

Let's now look at permeability models from the posterior distribution. The images in Figure 1.5 show horizontal slices through the permeability model that best fit the seismic data (likelihood function reached a maximum). The top image row shows permeabilities and the bottom row shows lithologies. The horizontal slices are located $8 \mathrm{~m}$ above, $4 \mathrm{~m}$ above, $0 \mathrm{~m}$, and $4 \mathrm{~m}$ below the location of the $\mathrm{CO}_{2}$ injector; the injector depth at this location is approximately $1428 \mathrm{~m}$. The permeabilities are plotted using a logarithmic color scale. Note that the permeabilities range up to values of $150-160$ millidarcies. The largest permeabilities are observed 4 and $8 \mathrm{~m}$ above the injector. 


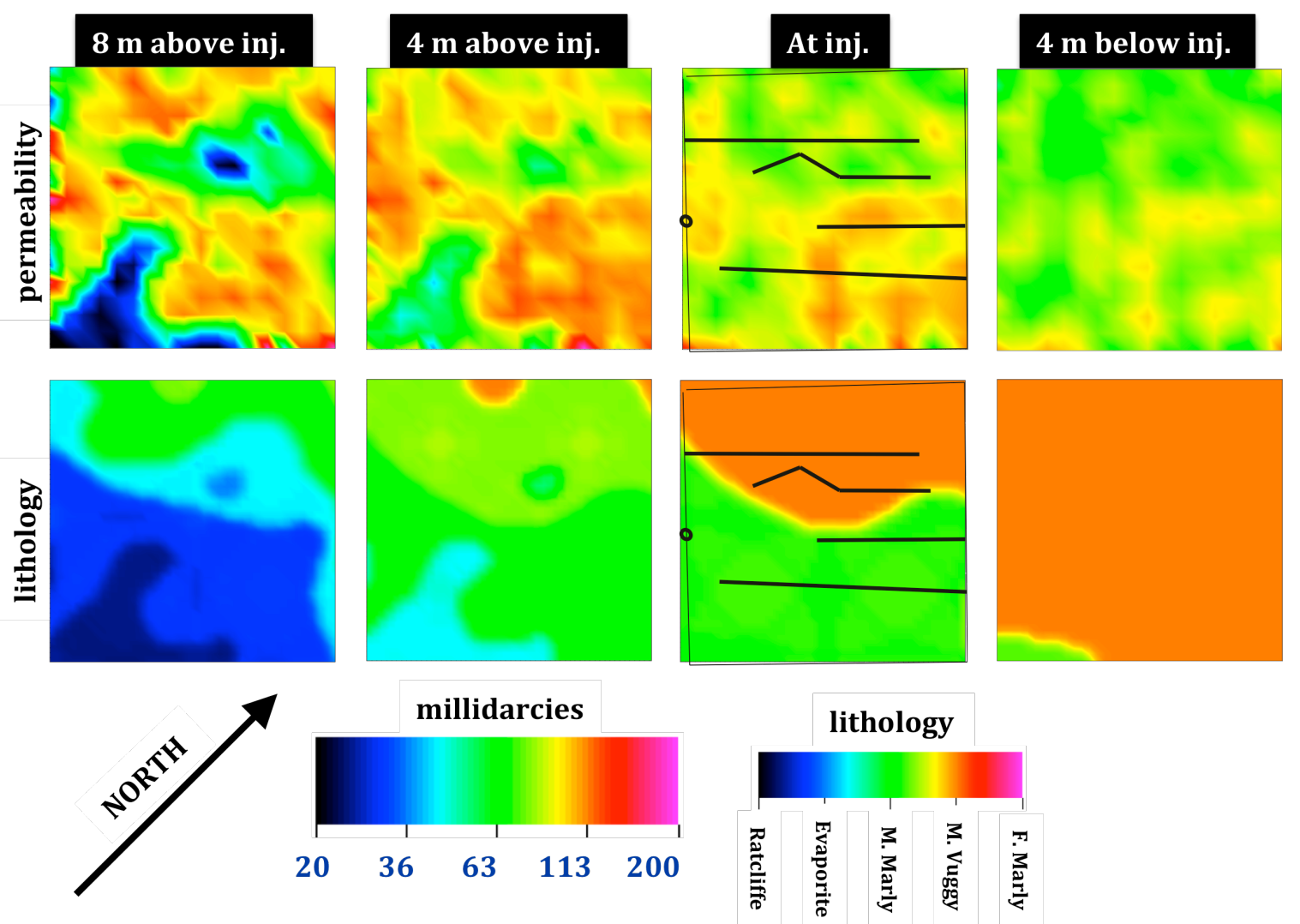

Figure 1.5. The top row of images shows the most likely permeability model identified by the MCMC inversion; the most likely model is the model that exhibits the smallest misfit between the observed and calculated seismograms. The images on the second row show the lithologies present. The image planes are horizontal and located at the elevation of the $\mathrm{CO}_{2}$ injector, $4 \mathrm{~m}$ and $8 \mathrm{~m}$ above the injector and $4 \mathrm{~m}$ below the injector. The $\mathrm{CO}_{2}$ saturation color bar is at the top right corner of the image. The permeabilities are shown in millidarcies, on a logarithmic scale.

We next examine the full ensemble of models in the posterior distribution. Figure 1.6 shows the mean (top row) and standard deviation (bottom row) of all the permeability models in the posterior distribution, i.e., models with iteration number greater than 5000 . Comparing the top row of images in Figures 1.5 and 1.6, we can see that the permeability images are very similar. This suggests that most of the models in the posterior are similar to one another. The variability between models can be evaluated by looking at the standard deviation images, bottom row of images in Figure 1.5. High permeability zones show a permeability of about $120+/-25$ millidarcies. Intermediate permeability zones show a permeability of about $80+/-12$ millidarcies and low permeability zones show a permeability of about less than $20+/-6$ millidarcies. 


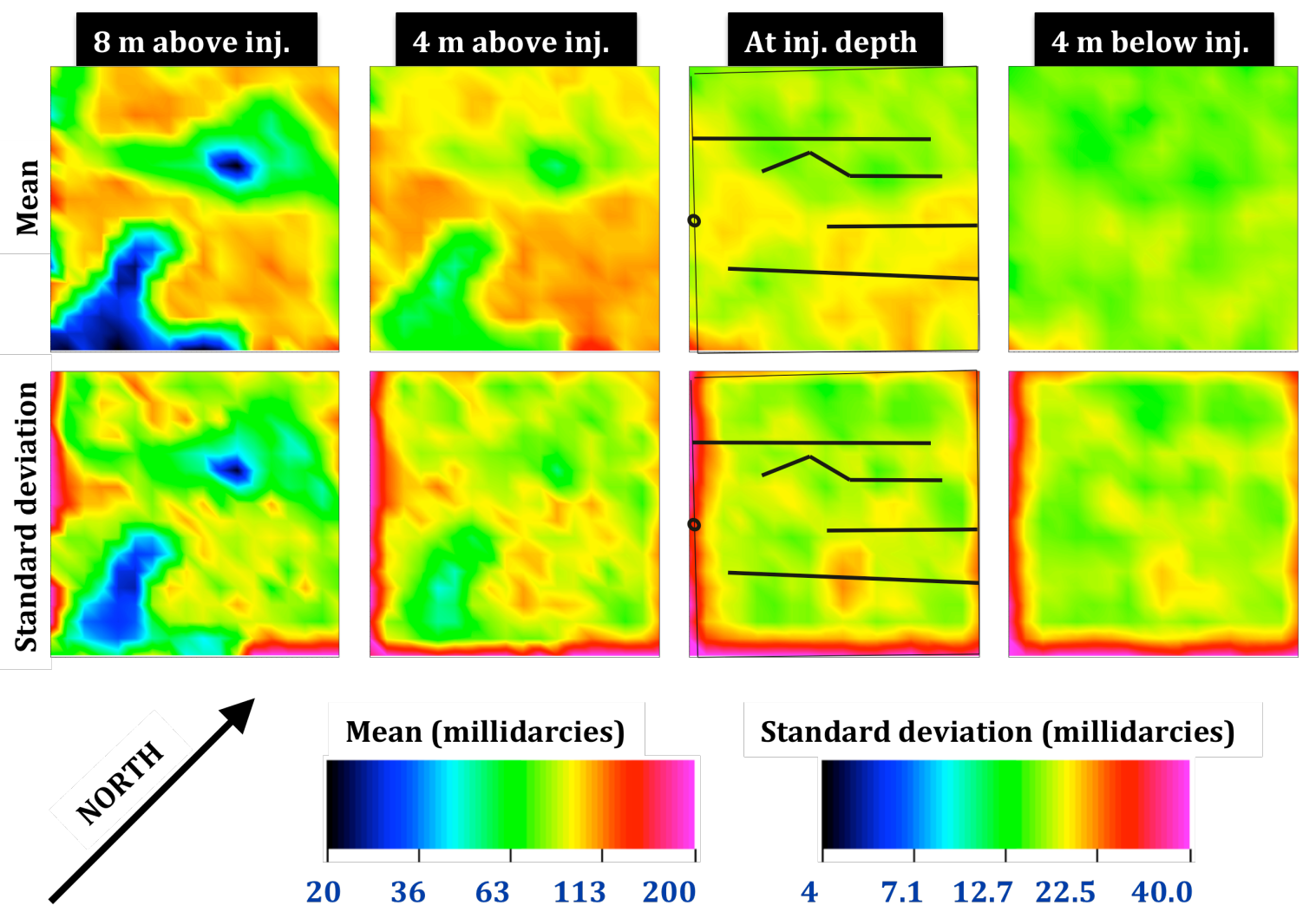

Figure 1.6. The images show the mean and standard deviation of all the permeability models with iteration number greater than 5000 .

The band of large standard deviation along the edges of the pattern is primarily caused by a lack of seismic data along the edges. The region of interest has been rotated 45 degrees clockwise in order to make better use of the rectilinear grid that the flow simulation assumes. After rotation, some of the seismograms near the edges fall outside of the computational grid and are not available to constrain the permeability values near the edges. The lack of data constraints produces large standard deviation band along the edges of the images.

We now look at the differences in the prior and posterior distributions of porosity and permeability. Porosity histograms are shown in the top row of Figure 1.7. The top left histogram shows the prior porosity distribution for the Midale Marly and Vuggy, i.e., the probability distribution that expresses the porosity uncertainty before the seismic data is used. This distribution comes from Cenovus' calibrated model. The top center histogram shows the porosity distributions of core data (provided by Erik Nickel, Saskatchewan Ministry of Energy and Resources). The top right histogram shows the porosities in the posterior distribution, i.e., the probability distribution that expresses the porosity uncertainty after the seismic data has been used to guide the search. The bottom row histograms show the corresponding permeability distributions. 

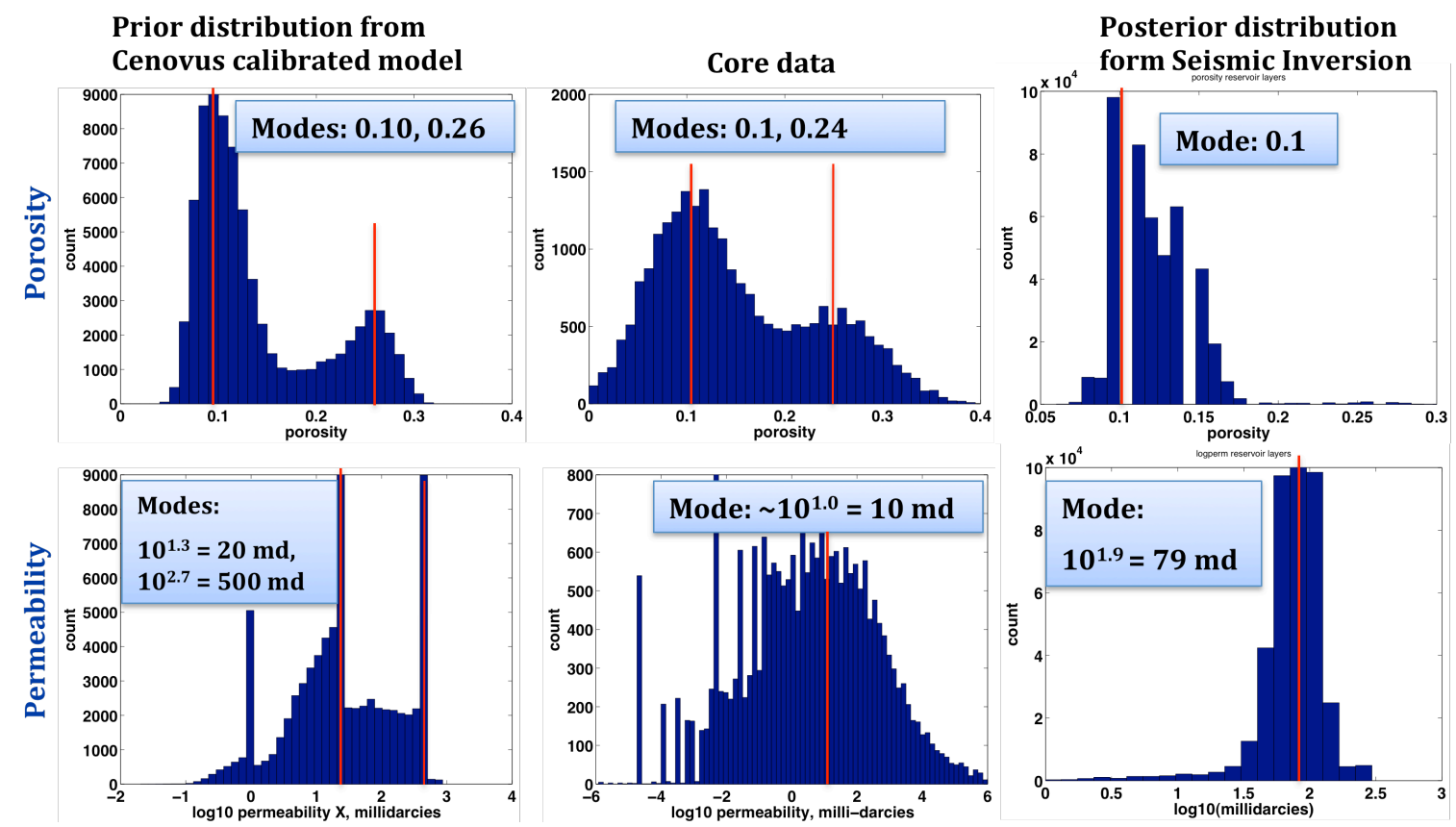

Figure 1.7 shows histograms of porosity and permeability distributions in the Midale formation (Marly and Vuggy units are combined in the plots). The histograms on the left show the prior distributions used to constrain the inversion; these distributions are present in a reservoir model calibrated by Cenovus to match production history at the Weyburn field. Histograms based on core data are shown in the center. Histograms corresponding to the inversion results are shown on the right side.

These histograms indicate that the MCMC inversion is changing the permeabilities indicated by the prior distribution, while the porosity distribution is not changing very much. For example, the prior permeability distribution has modes (permeability values that have the highest number of observations) of about 20 and 500 millidarcies. In contrast, the posterior distribution mode is about 80 millidarcies. This value is also about a factor of 8 higher than the mode in the core data distribution. These histograms suggest that the seismic data is adding information and value by allowing the MCMC inversion to discriminate between the "good" and "bad" permeability realizations.

The prior and posterior porosity distribution both show a mode of 0.1 , thereby suggesting negible change. This means that posterior probability is mainly informed by the prior probability, i.e., the seismic data is not providing new information. This is probably due to the fact that the changes in seismic impedance caused by super-critical $\mathrm{CO}_{2}$ primarily depend on the spatial distribution and magnitude of permeability and less on the porosity distribution. 

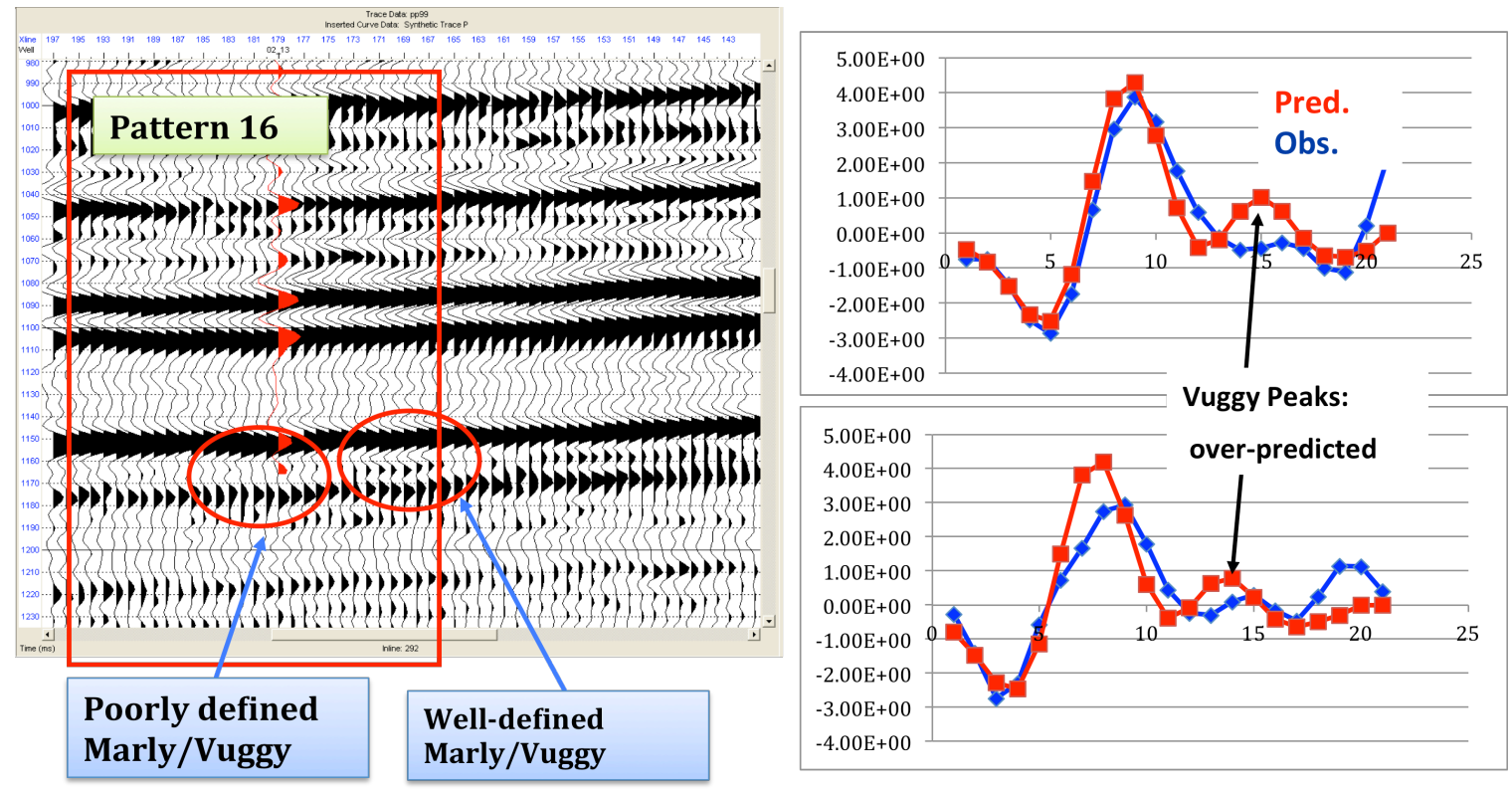

Figure 1.8. Seismogram on the left shows the seismograms measured within the margins of pattern 16, indicated by the red rectangle. The red ellipses highlight regions where the Marly through and Vuggy peak are well defined and poorly define. The seismogram on the left provided by D. White, Geological Survey of Canada. The plots on the right show examples of predicted (red) and observed (blue) waveforms. Note that some of the peaks are overpredicted.

We consider these results preliminary because there are several factors that degrade the accuracy of the results. The thickness of the Midale Evaporite ranges between 1 and $5 \mathrm{~m}$ in the pattern. The distance between nodes in the flow simulation grid is $4.3 \mathrm{~m}$ in the depth direction. This means that the Evaporite layer is not continuous in the simulation grid and its confining effect is not adequately reproduced during the flow simulations. This problem will be fixed in future seismic inversions by forcing the Ratcliffe layer (located immediately above the Evaporite) to have the same very low permeability as the Evaporite, thereby creating a continuous confining layer above the Midale Marly. An alternative approach would reduce the distance between grid nodes from about 4.3 to 1.0 $\mathrm{m}$ in order to accurately reproduce the laterally continuous nature of the Evaporite. We did not choose this alternative because our inversion run-times are currently about 12 days and this change approximately would quadruple the run time.

A second factor is also related to the coarseness of the grid in the depth direction. The Midale Marly average thickness is about $6 \mathrm{~m}$. This means that, on average, only one layer of nodes is used to simulate flow in the Marly. The coarse node distance may lead to inaccuracies in the flow calculations. We are currently conducting flow simulations to assess the significance of this issue.

A third factor is best explained by looking at Figure 1.8. The plots on the right compare predicted and observed waveforms. The predicted waveforms were calculated using the "best likelihood" model shown in Figure 1.5. Note that the peak amplitudes associated with the top of the Midale Vuggy are too large relative to the observations. This means 
that the sections of the predicted waveforms that correspond to the Midale Marly and Vuggy do not closely match the observations. This poor fit is observed in some seismograms while others exhibit a reasonable fit.

We believe that the primary reason for the sporadically poor fit is that seismic properties of the Midale reservoir are spatially variable but our current algorithm assumes homogeneous values of bulk modulus, shear modulus and density for each layer. The baseline (pre- $\mathrm{CO}_{2}$ injection) seismograms on the left side of Figure 1.8 show that the Vuggy peak and Marly trough are well defined in some parts of the pattern and poorly defined in others (seismogram provided by D. White, Geological Survey of Canada). This variability supports our hypothesis that the seismic properties are spatially variable.

Our proposed fix for this issue is to break up our seismic inversion approach into two steps. First, we will propose spatially variable realizations of bulk/shear moduli and density. We will use our MCMC algorithm and the pre- $\mathrm{CO}_{2}$ seismic data to find those models that best fit the seismic data. We will then compute the mean and standard deviation (bulk/shear moduli, density) for all models in the posterior distribution. We believe that this approach will identify seismic property models that are much more realistic than the models we currently use for inversion (based on core measurements). We think that the new models will properly account for the spatial heterogeneity of seismic properties within the reservoir. In the second step, we will use the mean models and lock in their seismic properties while allowing only the porosity and permeability to change. We will use seismic data collected during $\mathrm{CO}_{2}$ injection to identify the best permeability models. We hope that this two-step approach will produce better waveform predictions that closely match the observations along the full waveform length.

\section{Computational Expense}

Perhaps the greatest challenge associated with the use of our stochastic inversion approach is its computational expense. Almost all the expense is in running the flow simulator that predicts reservoir conditions caused by injection/extraction operations.

The inversion described here required about 5000 iterations for the Markov chains to reach convergence. A total of 28,000 porosity/permeability models were evaluated by performing flow simulations for each. About 4000 of the models became part of the posterior distribution (i.e., the solution to the stochastic inverse problem), and the rest were discarded. Each run used 112 processors, running for about 9 days (processor time). The wall clock time needed to complete the run was about 12 days. The wall clock time is larger than the processing time because we used a multi-user machine where each run is limited to 16 hours of run time; the runs have to be re-submitted and wait in he queue for a few hours before execution resumes.

\section{Seismic Inversion Summary}

We have made changes to our seismic modeling approach to improve the accuracy of the predicted waveforms. We have also conducted a test of our stochastic inversion approach using seismic data from pattern 16, Phase 1A. The MCMC stochastic inversion identified reservoir models (porosity and permeability) that best fit the "observed" 
seismic data. Histograms of prior and posterior permeabilities suggest that the seismic data provides information that discriminates between the "good" and "bad" permeability realizations. The computational expense is large, requiring about 12 days to complete a run. We have identified a couple of factors that degrade the accuracy of the inversion results. The coarseness of the computational grid makes the Evaporite layer to appear discontinuous when in reality is continuous across the pattern of interest. We have also identified the need to obtain better estimates of seismic properties (bulk and shear moduli, density), and propose to do a stochastic inversion to obtain them using the pre$\mathrm{CO}_{2}$ injection seismic data.

\section{Chapter 2: An Approach for the Inversion of Geochemical Parameters}

This chapter presents an approach for evaluating the magnitude and spatial distribution of geochemical parameters associated with $\mathrm{CO}_{2}$ injection within the Weyburn reservoir. These parameters specifically include the rates of dissolution/precipitation reactions associated with key mineral phases, and the spatial distributions of these rates and their relationship with lithology and permeability distributions. The proposed approach includes:

1. Constructing a realistic synthetic problem to understand key constraints on waterrock reactions and effects of heterogeneity;

2. Applying an inversion algorithm to the synthetic test problem (on a scale comparable to a single pattern) to assess efficacy, particularly in the context of limited spatial resolution inherent in monitoring data;

3. Apply the inversion algorithm across a larger scale (i.e., multiple patterns) to facilitate comparison with a larger number of monitoring locations.

\section{Reservoir Geochemistry Model}

The Vuggy and Marly units - the permeable constituents of the reservoir - consist primarily of dolomite and calcite, with lesser abundances of aluminosilicate minerals such as feldspars, illite, and kaolinite. To posit a plausible geochemical model of the reservoir with which to inform the geochemical parameter inversion calculations, the brine water quality data set, including baseline data as well as data collected during subsequent monitoring events following the commencement of $\mathrm{CO}_{2}$ injection, must be reconciled with the inferred mineral abundances and presumed reactivities of key mineral phases.

Monitoring data were collected beginning in August 2000 (Baseline sampling event). The Baseline data set as well as data from subsequent sampling events through Monitoring 11 (September 2004) were speciated using the PHREEQC geochemical 
model (Parkhurst and Appelo, 1999) to assess the possible impact of $\mathrm{CO}_{2}$ injection across the reservoir. Initial speciation of 328 water complete water samples collected from multiple wells during these sampling events indicates that the majority of the samples are thermodynamically highly supersaturated with respect to calcite (Figure 2.1), based on laboratory-measured $\mathrm{pH}$ samples. It is likely that these samples reflect some off-gassing of $\mathrm{CO}_{2}$ under ambient atmospheric temperature and pressure during sample collection, recovery, handling, and analysis, resulting in a $\mathrm{pH}$ rise and hence calculated calcite supersaturation which is not indicative of in situ conditions (Emberley et al., 2005). This explanation is supported by comparing measured $\mathrm{pH}$ values with a set of subsequent of downhole $\mathrm{pH}$ measurements collected during some of the early monitoring events, which reveals laboratory-measured $\mathrm{pH}$ values that are appreciably higher than those obtained via downhole probe at $\mathrm{pH}$ values less than 7.0 (Figure 2.2), presumably those samples characterized by the highest $\mathrm{CO}_{2}$ partial pressures and hence the most likely to be affected by off-gassing.

To compensate for the loss of $\mathrm{CO}_{2}$, and hence the presumably skewed $\mathrm{pH}$ values across the 328 samples, PHREEQC was used to acidify individual samples. At a fixed alkalinity, this implies the addition of $\mathrm{CO}_{2}$ to the solution composition. To constraint this calculation, $\log$ saturation indices for calcite were reduced to +0.3 in a majority of the water samples which were initially identified as being highly supersaturated. The $\mathrm{pH}$ in a small subset of samples with calcite log saturation indices between +0.3 and +0.5 was not adjusted because of difficulty reconciling total alkalinity and bicarbonate alkalinity. The effect of this adjustment on computed $\mathrm{pH}$ versus downhole $\mathrm{pH}$ and on carbonate saturation indices is shown on Figures 2.3 and 2.4, respectively. This adjusted water quality data set comprises the brine chemistry data, including concentrations of dissolved $\mathrm{CO}_{2}$, with which reactive transport model results may be compared and hence assessed, as discussed below.

\section{Reactive Transport Simulation of $\mathrm{CO}_{2}$ Injection into a Heterogeneous Reservoir}

A geochemical model for the brine chemistry which assumes buffering of solution $\mathrm{pH}$, $\mathrm{Ca}$, and to some extent $\mathrm{CO}_{2}$ by calcite and dolomite (and, to a limited extent, the concentration of Si by aluminsilicates) was used to inform an idealized reactive transport model for a 1-km x 1-km section of the reservoir. This model was developed to assist in constraining the geochemical parameter inversion by providing a plausible $\mathrm{CO}_{2}$ injection, dissolution, and reaction scenario which is consistent with measurements (brine chemistry data) that can be used as a "synthetic truth data" set with which to test the inversion algorithm.

The model is based on two postulated vertical water injection wells and a horizontal $\mathrm{CO}_{2}$ injection well which act to perturb the pressure distribution and the geochemistry of the reservoir. Fluid flow, solute transport, and geochemical reactions for the idealized problem were simulated using the U.S. Geological Survey's PHAST simulator (Parkhurst et al., 2004). Although PHAST considers only single phase flow, we have attempted to capture the effect of a dissolving supercritical $\mathrm{CO}_{2}$ phase (i.e., additional $\mathrm{CO}_{2}$ mass in the system) by creating a fictitious $\mathrm{CO}_{2}$ fluid species that moves with the aqueous phase. 
Mass transfer from the $\mathrm{CO}_{2}$ fluid "phase" to $\mathrm{CO}_{2}(\mathrm{aq})$ was assumed to occur if the $\mathrm{CO}_{2}$ fugacity of the fluid within a given volume element was below a critical threshold value (e.g., equivalent to 73 bars). The molar concentration of the $\mathrm{CO}_{2}$ fluid in water at the $\mathrm{CO}_{2}$ injection well of approximately $11 \mathrm{~mol} / \mathrm{L}$ was based on a $\mathrm{CO}_{2}$ fluid density of 0.5 $\mathrm{gm} / \mathrm{mol}$ and a molecular weight of $44 \mathrm{gm} / \mathrm{mol}$.

Specific model constraints and assumptions included:

- A uniform grid spacing is employed, utilizing $20-\mathrm{m}$ by $20-\mathrm{m}$ volume elements.

- The reservoir thickness is $20 \mathrm{~m}$.

- The permeability field is modeled as Gaussian random field (Figure 2.5).

- The uniform porosity is assumed to be equal to 0.15 and is unaffected by mineral precipitation/dissolution reactions.

- Constant potential boundary conditions exist on all sides.

- Initial water chemistry in the reservoir is based on equilibration of the Baseline water composition with calcite, dolomite, and albite.

- For solute transport, the longitudinal dispersivity is $25 \mathrm{~m}$ and the transverse dispersivity is $5 \mathrm{~m}$.

- Reservoir mineralogy divided into dolomite-, calcite-, and silicate-buffered regions, generated by a Gaussian random field generator. Anhydrite is assumed to be present in some areas as well, overlapping the three.

- All precipitation/dissolution reactions are modeled as equilibrium reactions, with disordered dolomite and all silicate phases constrained as "dissolve-only". The $\log$ saturation index for each phase was selected from a normal distribution about 0.0 (or +0.3 for calcite), with a standard deviation of 0.25 , to mimic variably in the equilibrium condition (and hence, as an approximation, variability in the mineral precipitation/dissolution rate).

- An ion exchanger phase is also assumed to co-exist with the mineralogy, distributed via correlated Gaussian random field generator

The model was run for a total of 3,000 days, utilizing a 2-day time step. Water injection occurred for the first 2,000 days, followed by $\mathrm{CO}_{2}$ injection from 2,000 days through 3,000 days. Injection rates of $220 \mathrm{~m}^{3} /$ day and $95,000 \mathrm{~kg} /$ day were assumed for water and $\mathrm{CO}_{2}$, respectively, based on average rates, per well, provided in production data.

Model results are shown on Figures 2.5 through 2.12, including injection pressure (Figure 2.6), $\mathrm{CO}_{2}$ saturation (Figure 2.7) as calculated using the concentration of the postulated fluid $\mathrm{CO}_{2}$ fluid phase, simulated primary mineralogy (Figure 2.8), brine chemistry prior to $\mathrm{CO}_{2}$ injection (Figures $2.9-2.12$ ), brine chemistry after 1,000 days of $\mathrm{CO}_{2}$ injection (Figures $2.13-2.16$ ), and a comparison of brine chemistry at simulated monitoring well locations with monitoring data (Figures $2.17-2.20$ ). 


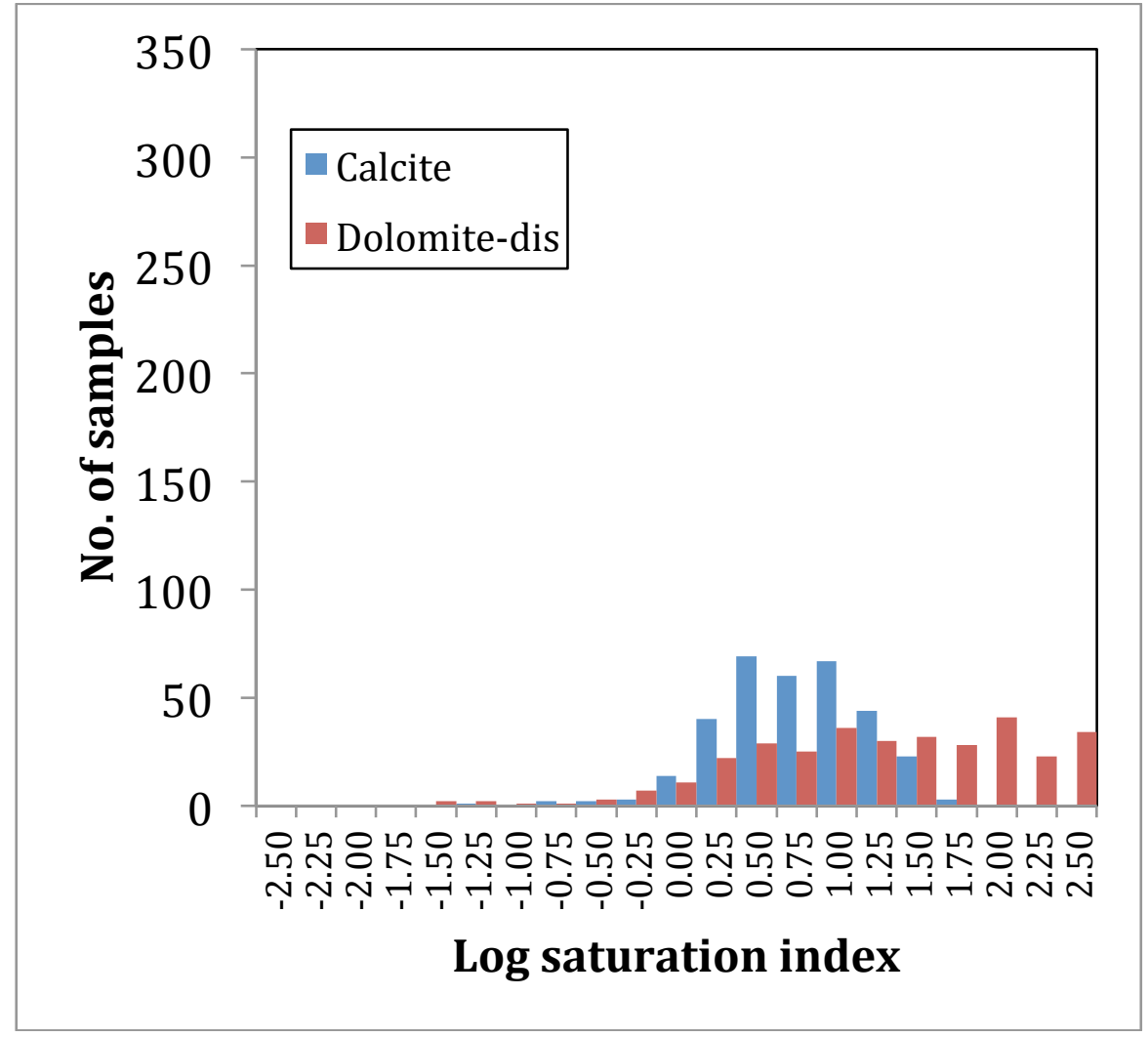

Figure 2.1. Calcite and disordered dolomite saturation indices in brine samples collected during monitoring events. 


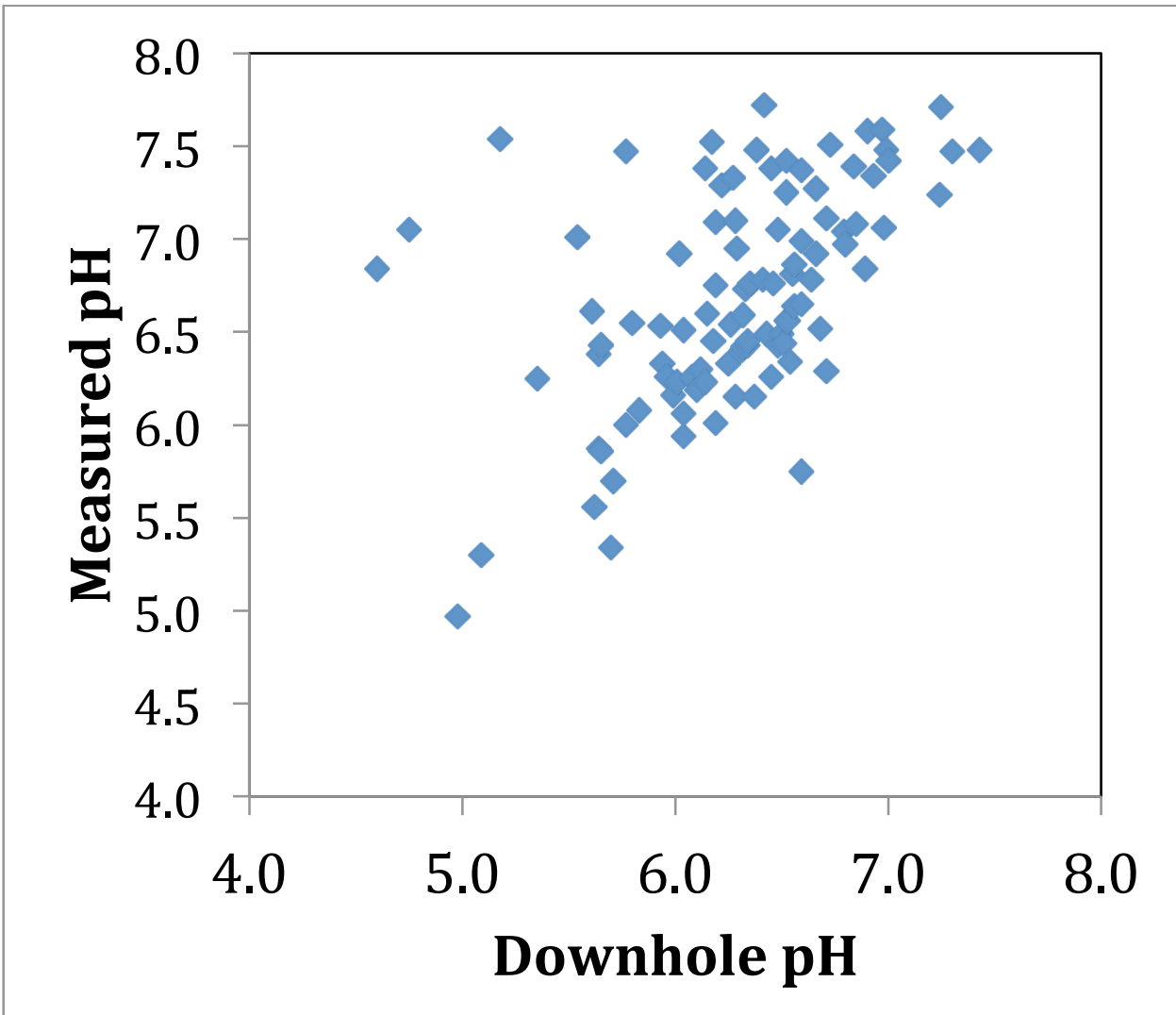

Figure 2.2. Laboratory-measured $\mathrm{pH}$ versus downhole $\mathrm{pH}$. 


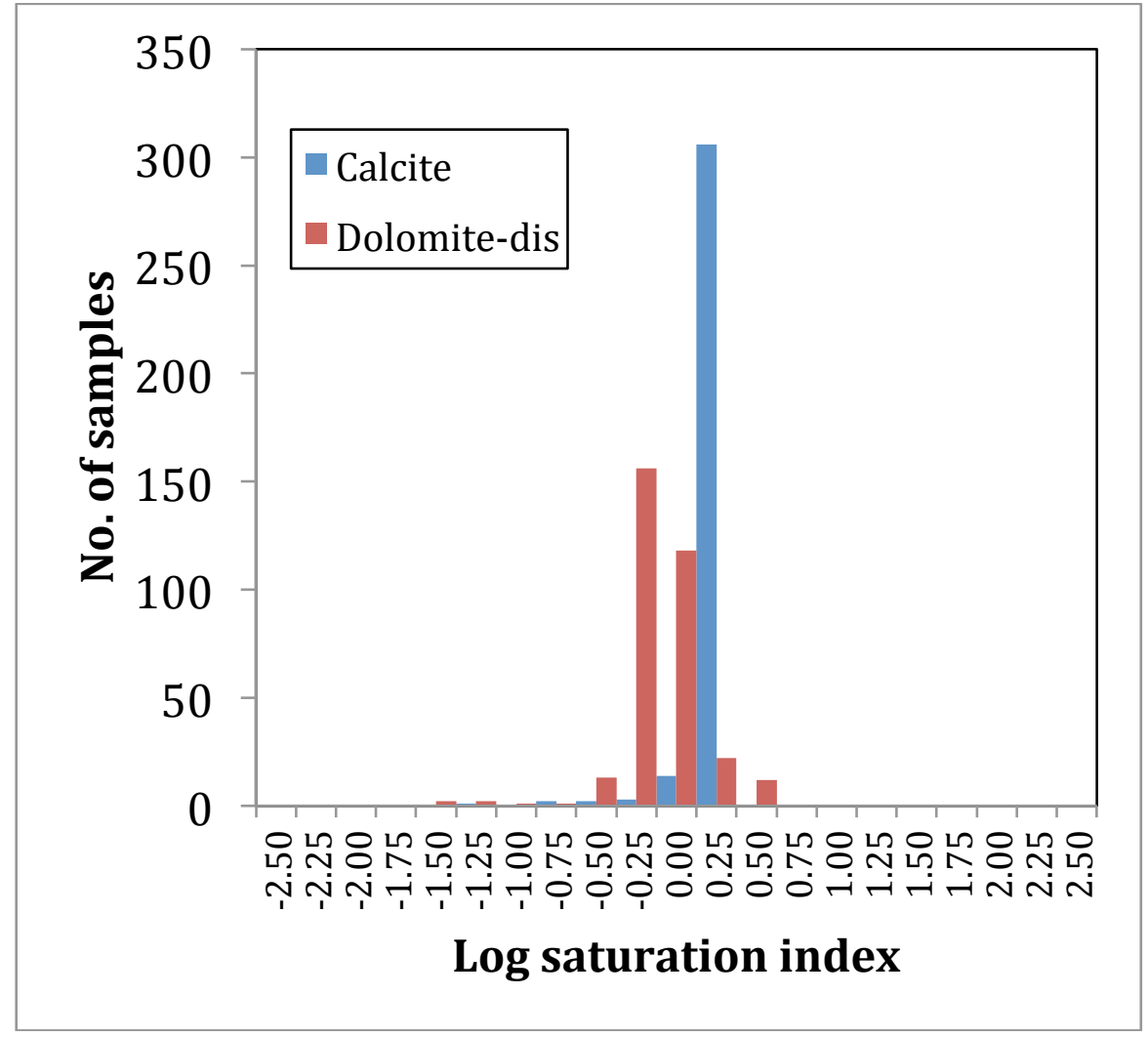

Figure 2.3. Calcite and disordered dolomite saturation indices in brine samples, corrected by simulated $\mathrm{pH}$ decrease $/ \mathrm{CO}_{2}$ addition. 


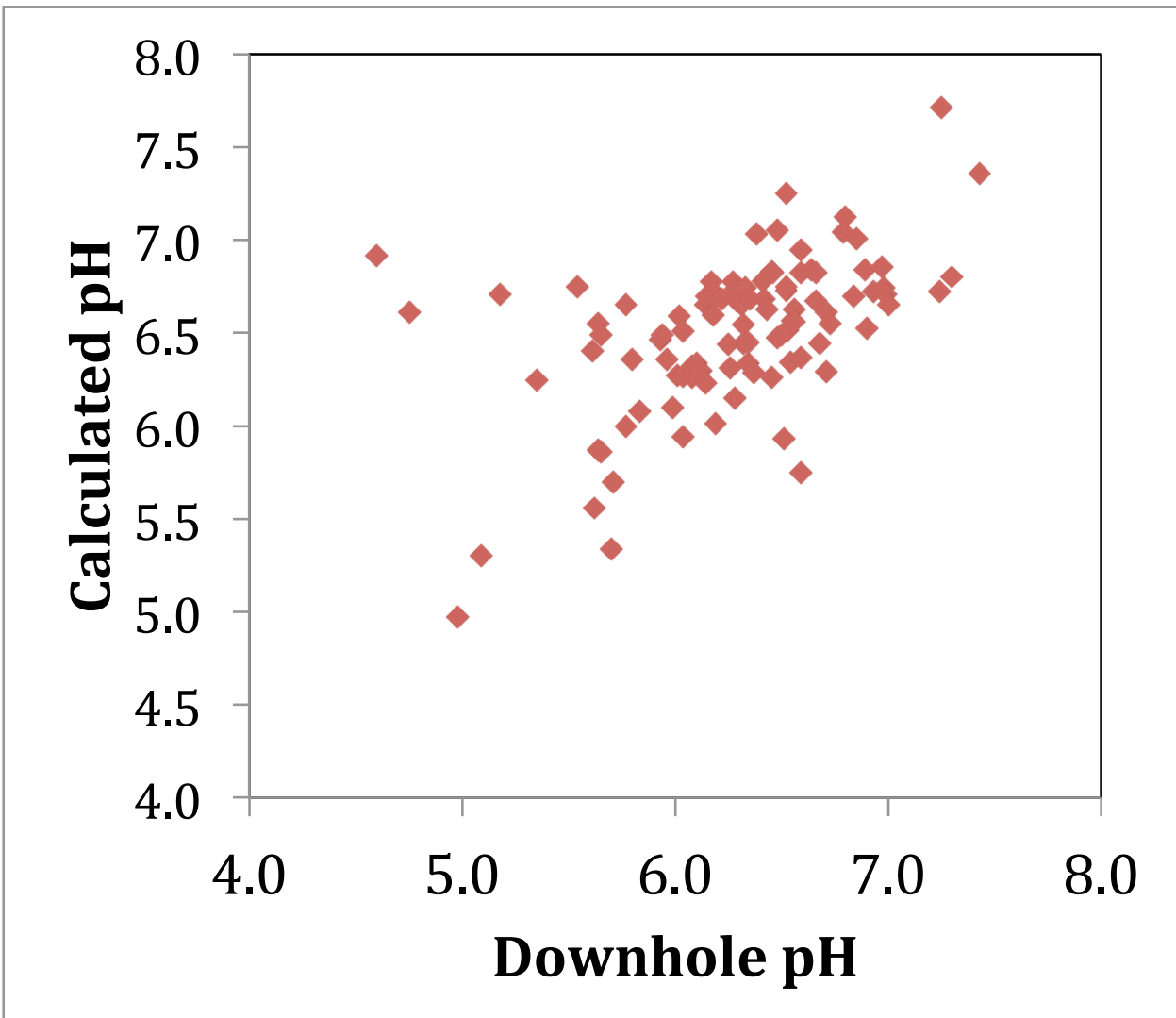

Figure 2.4. Modeled $\mathrm{pH}$ (pH-corrected samples) versus downhole $\mathrm{pH}$. 


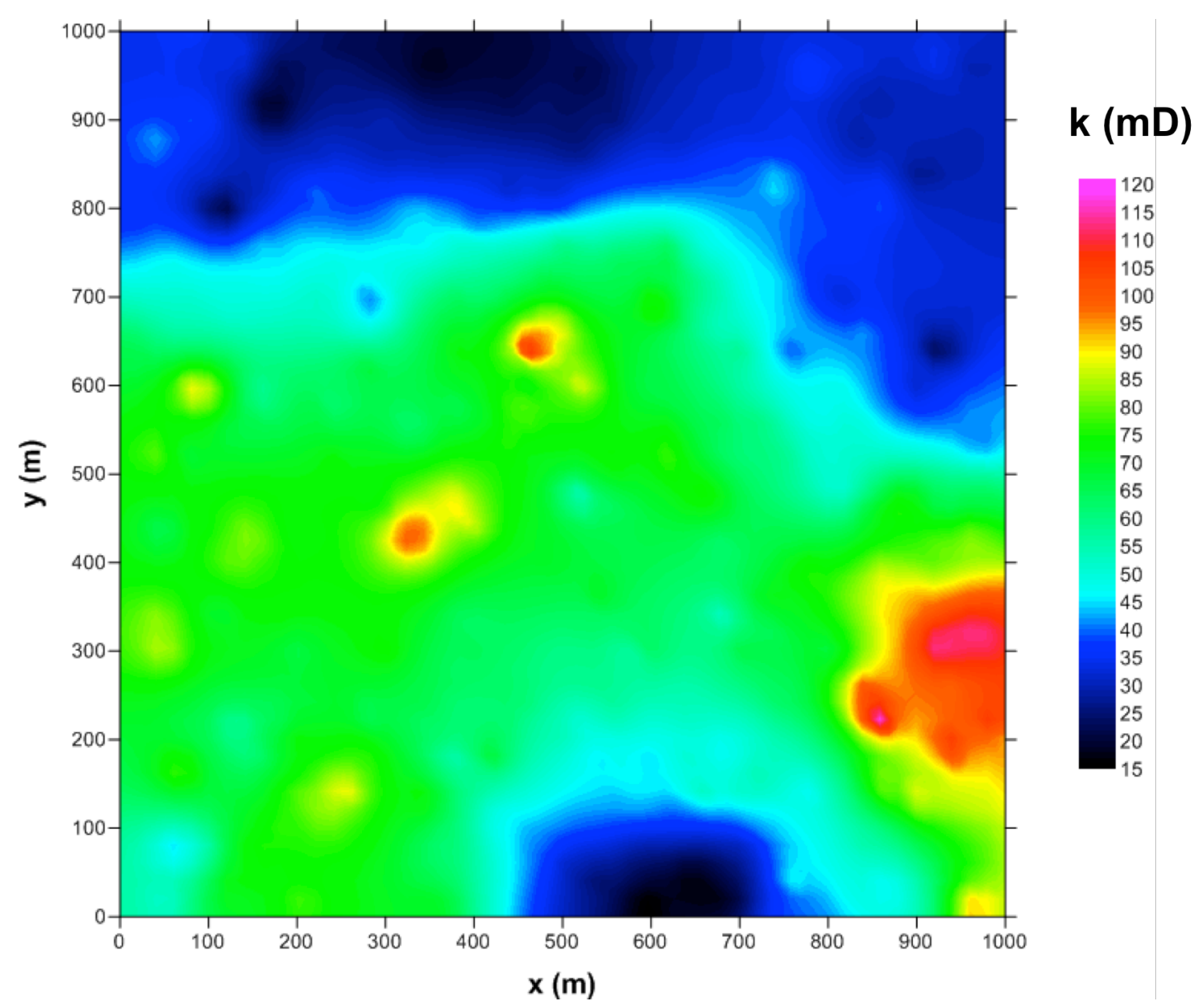

Figure 2.5. Distribution of reservoir permeability, represented by a Gaussian random field. 


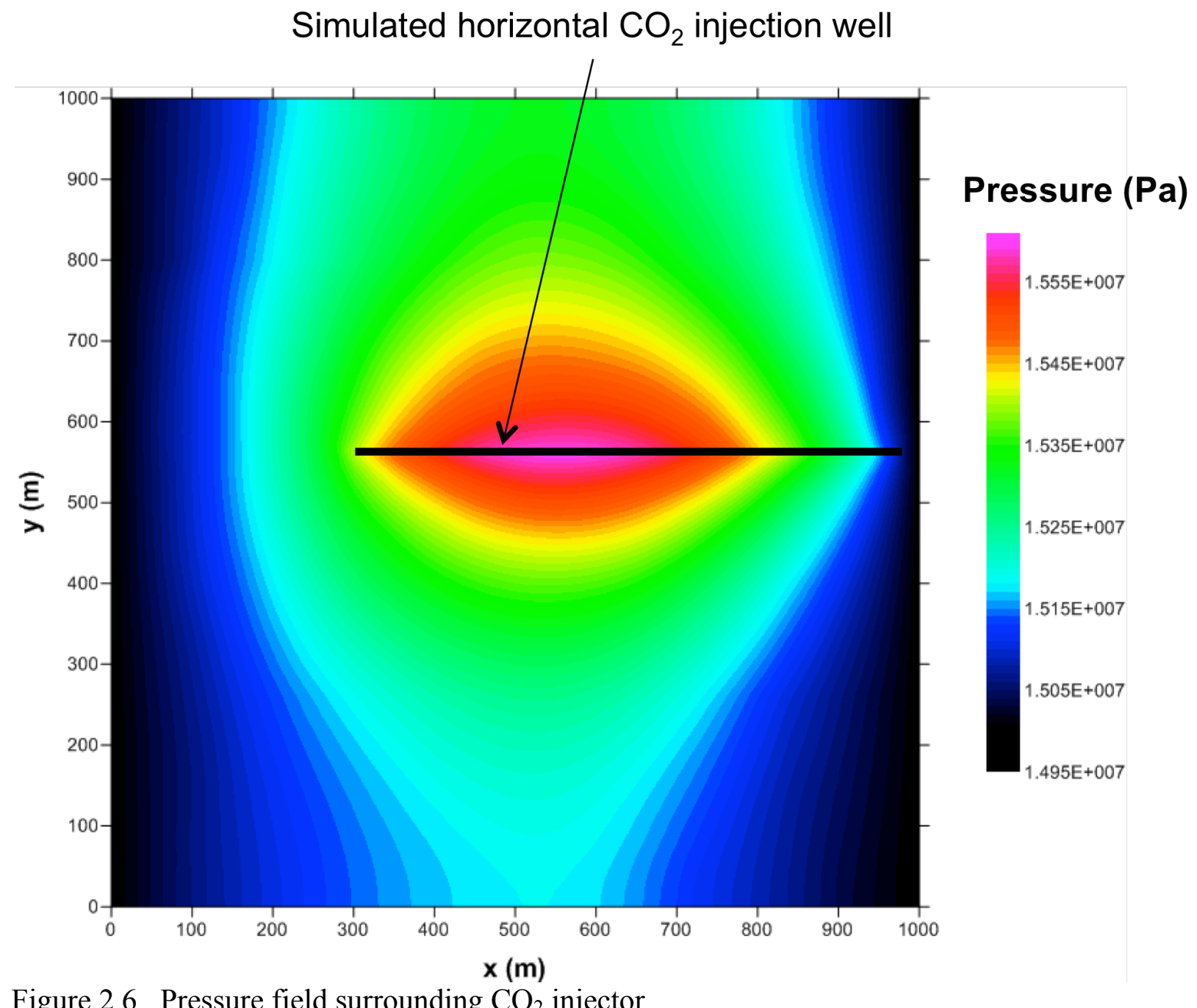

Figure 2.6. Pressure field surrounding $\mathrm{CO}_{2}$ injector. 


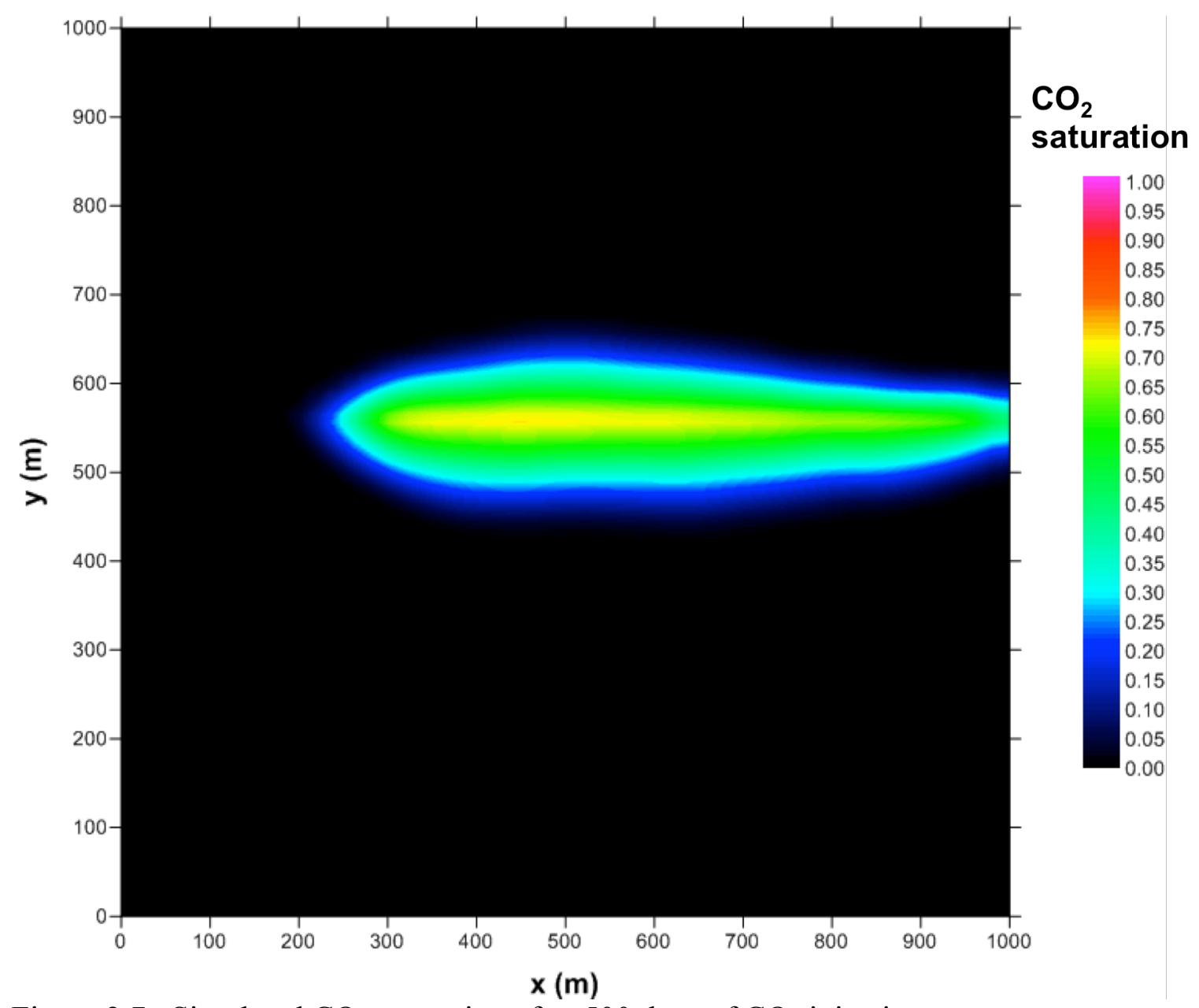

Figure 2.7. Simulated $\mathrm{CO}_{2}$ saturation after 500 days of $\mathrm{CO}_{2}$ injection. 


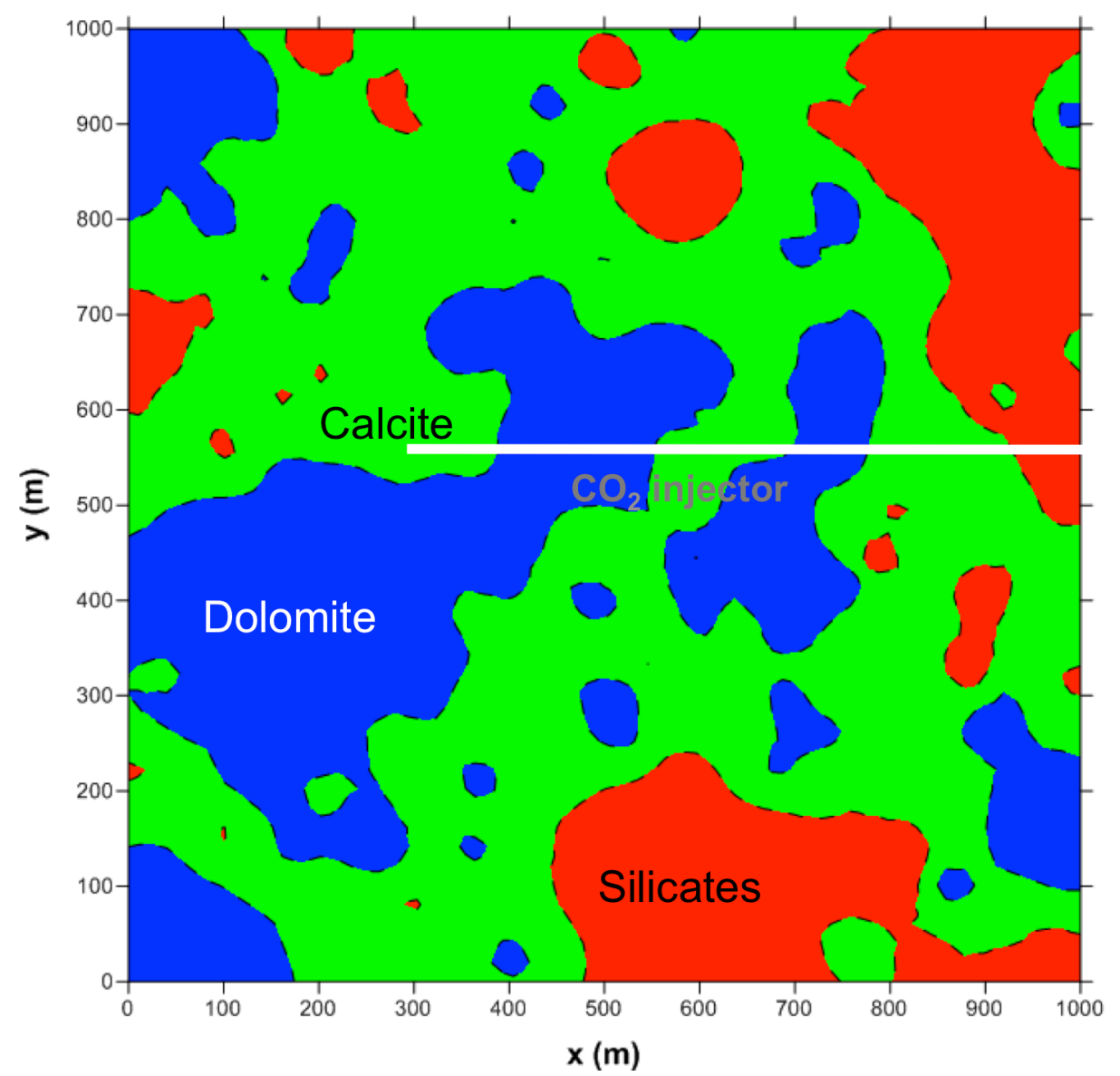

Figure 2.8. Simulated distribution of primary mineralogy. 


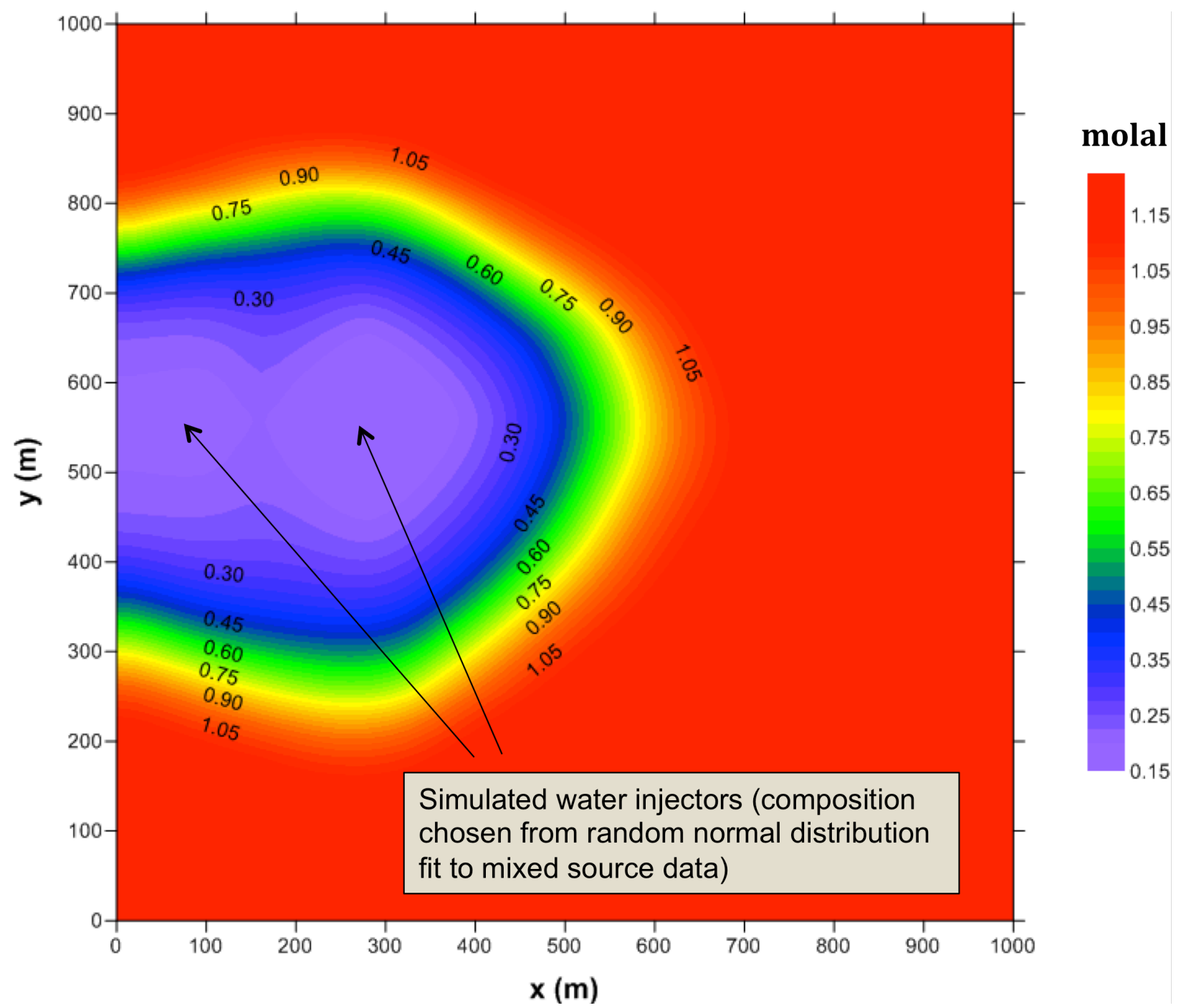

Figure 2.9. Chloride distribution at the end of water injection (2,000 days). 


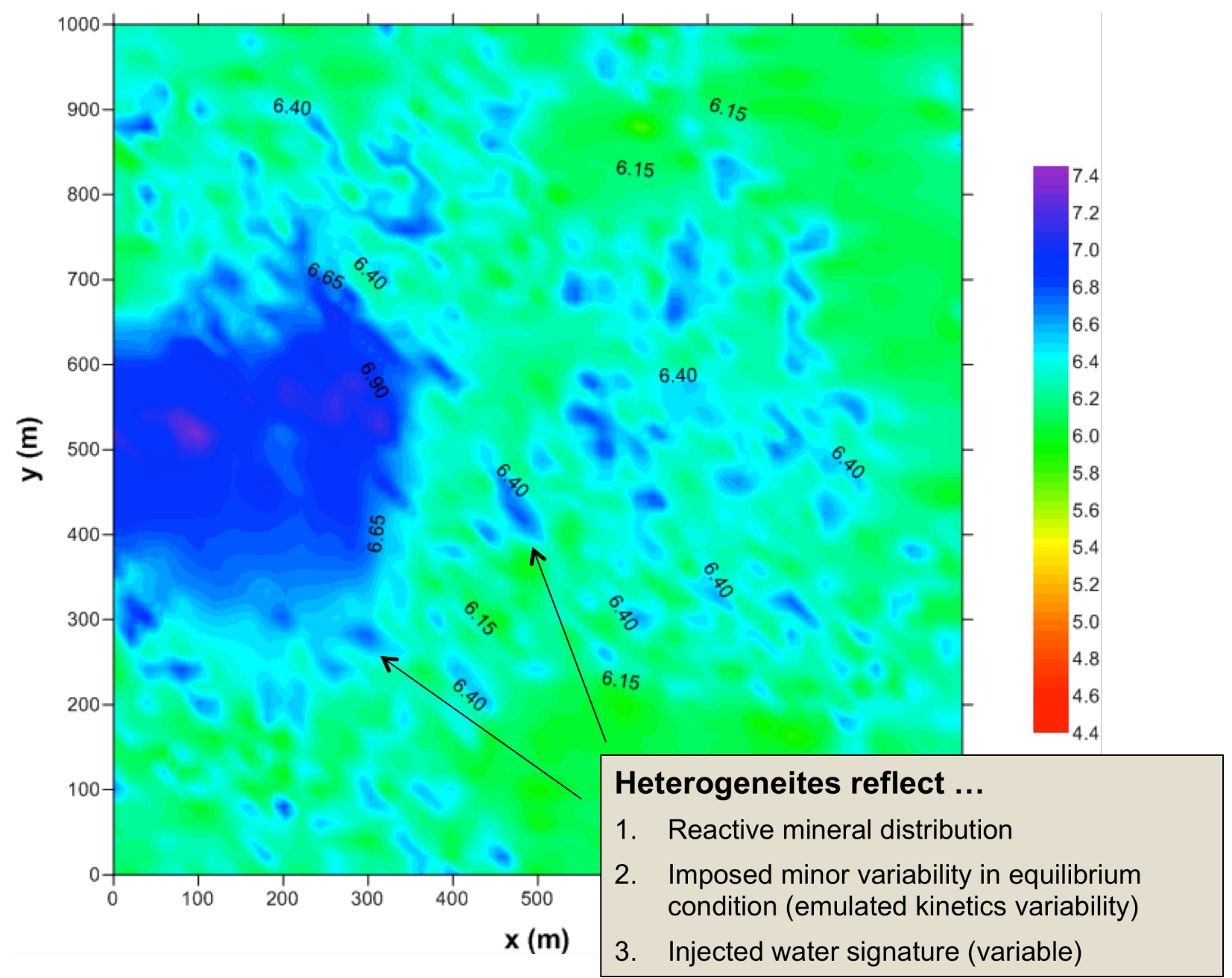

Figure 2.10. $\mathrm{pH}$ distribution at the end of water injection (2,000 days). 


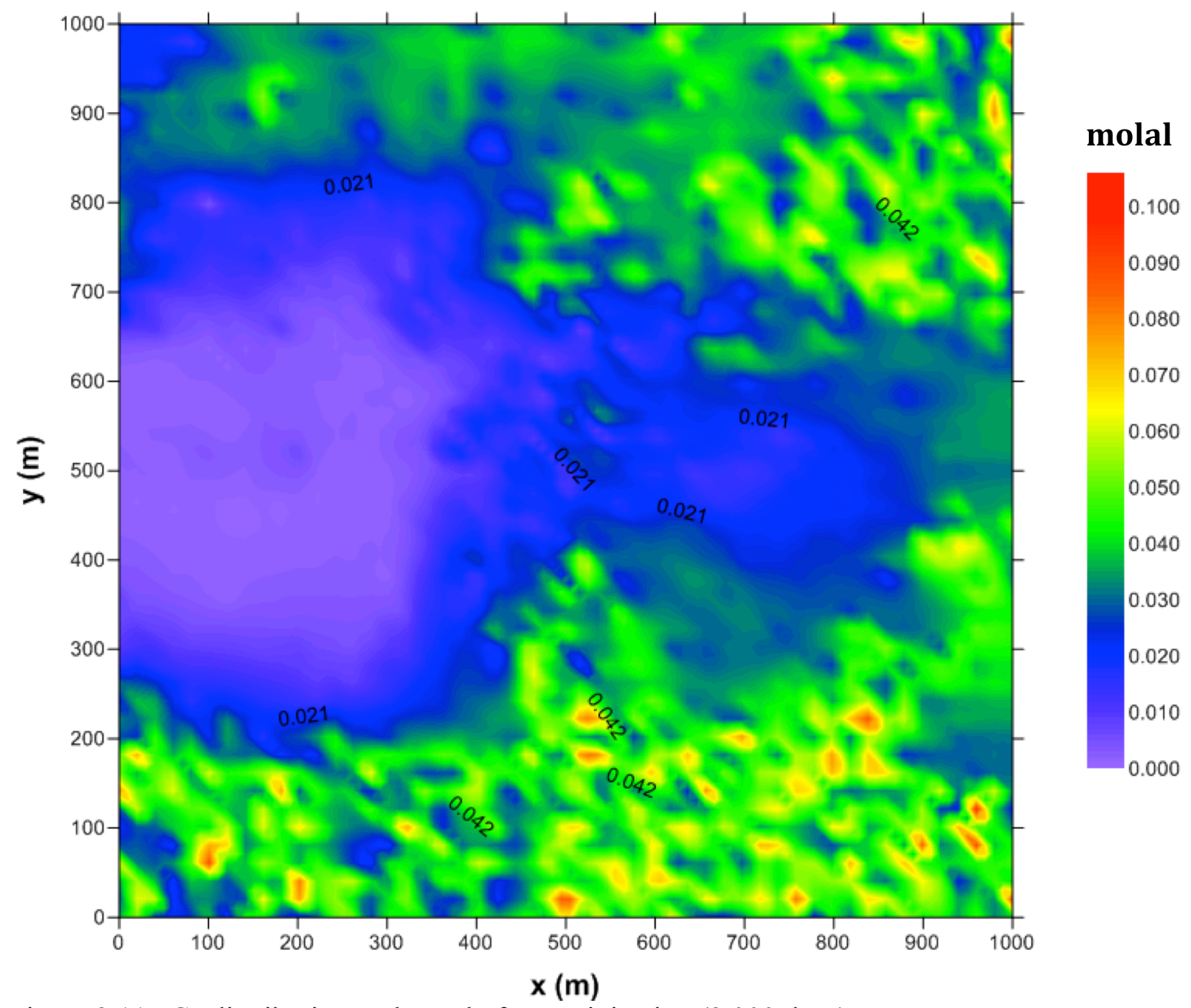

Figure 2.11. Ca distribution at the end of water injection (2,000 days). 


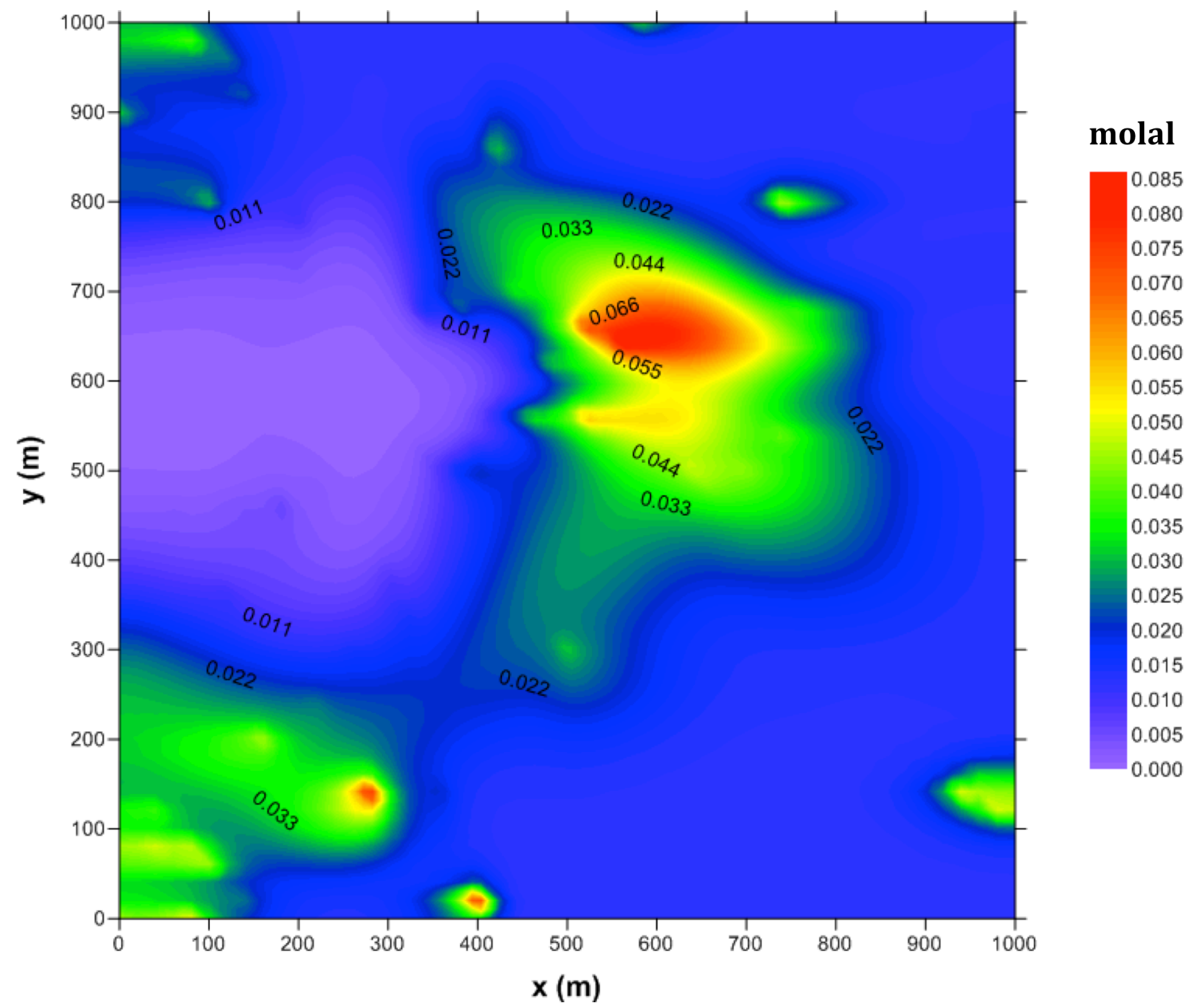

Figure 2.12. $\mathrm{Mg}$ distribution at the end of water injection (2,000 days). 


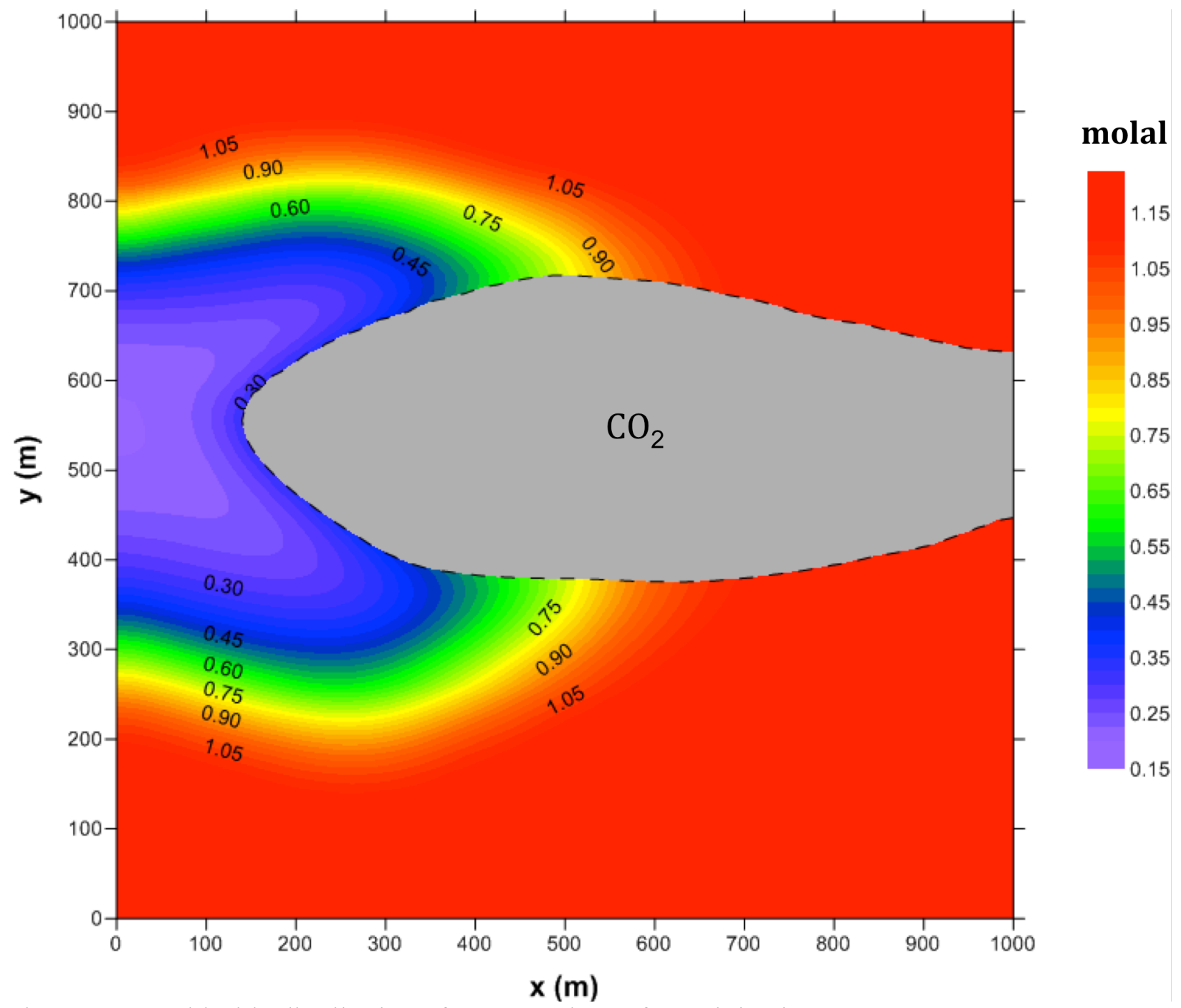

Figure 2.13. Chloride distribution after 1,000 days of $\mathrm{CO}_{2}$ injection. 


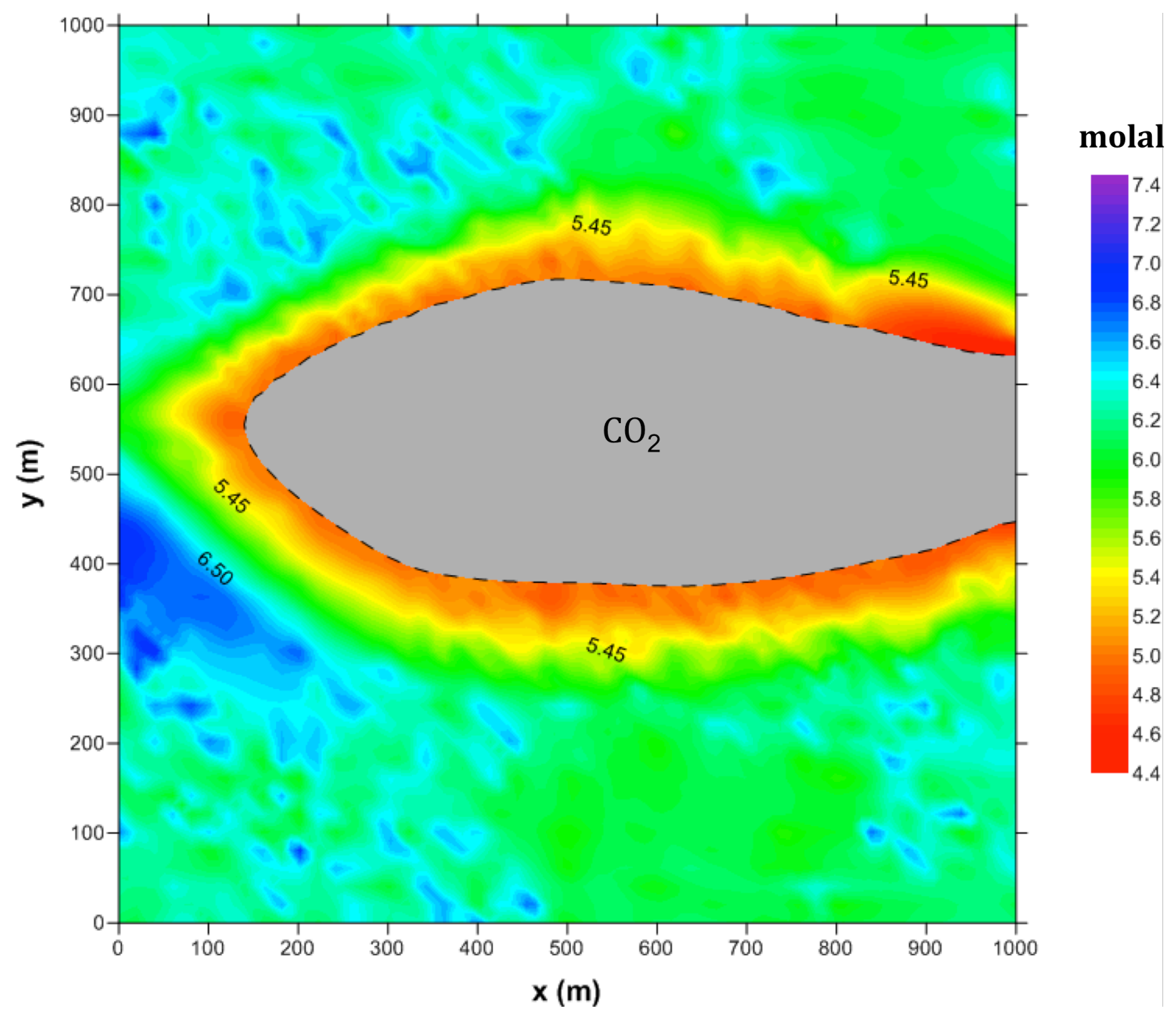

Figure 2.14. $\mathrm{pH}$ distribution after 1,000 days of $\mathrm{CO}_{2}$ injection. 


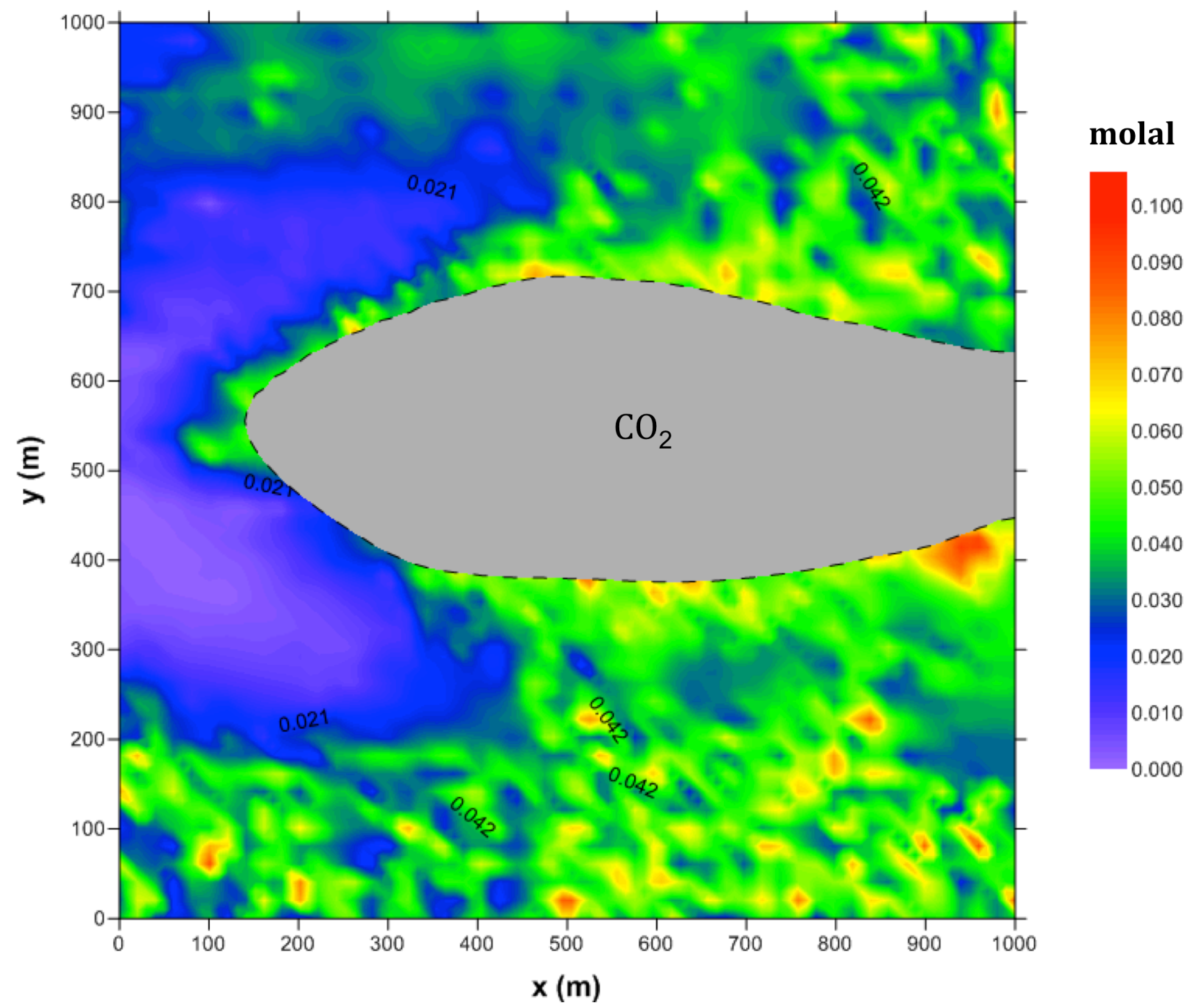

Figure 2.15. Ca distribution after 1,000 days of $\mathrm{CO}_{2}$ injection. 


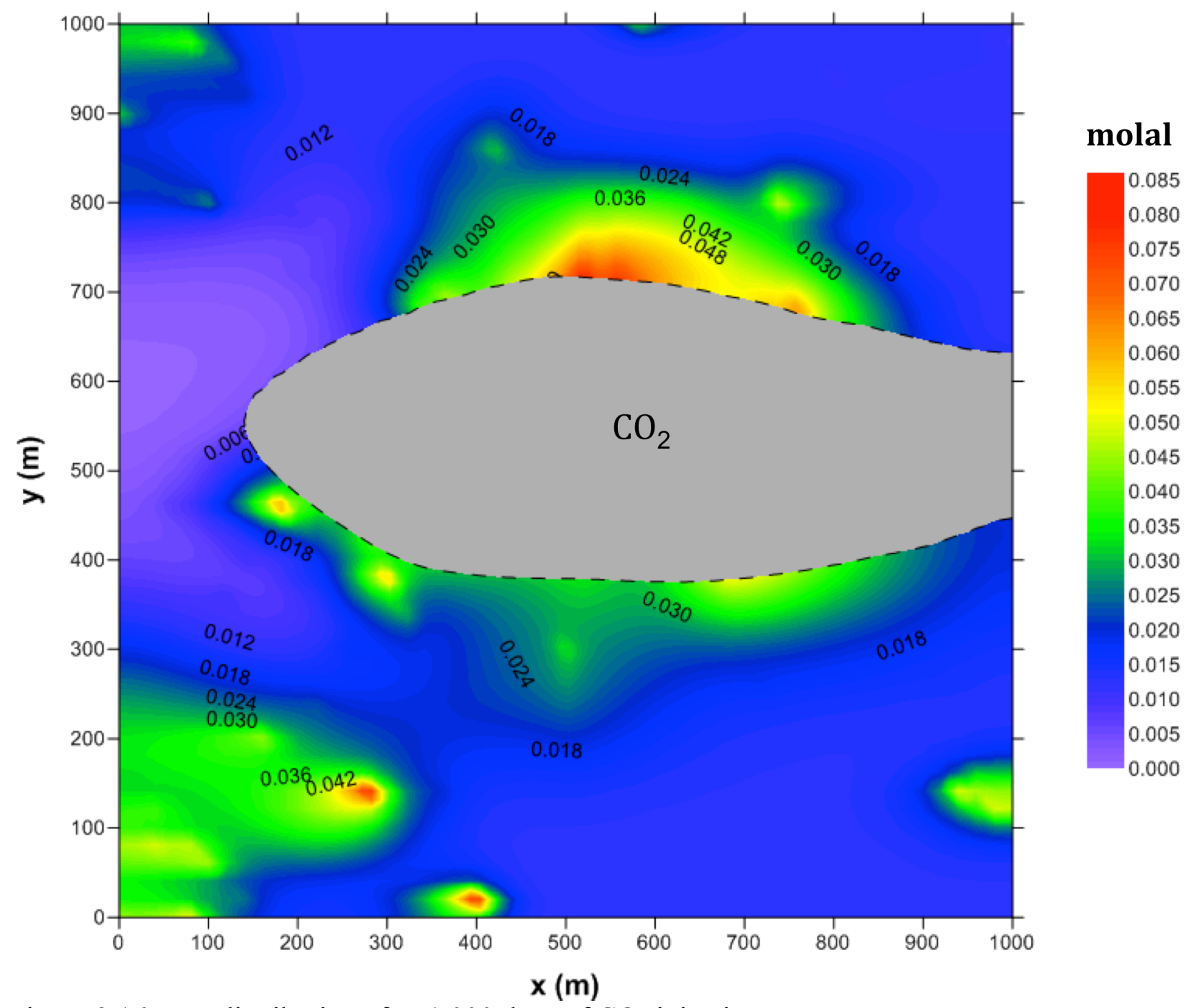

Figure 2.16. $\mathrm{Mg}$ distribution after 1,000 days of $\mathrm{CO}_{2}$ injection. 


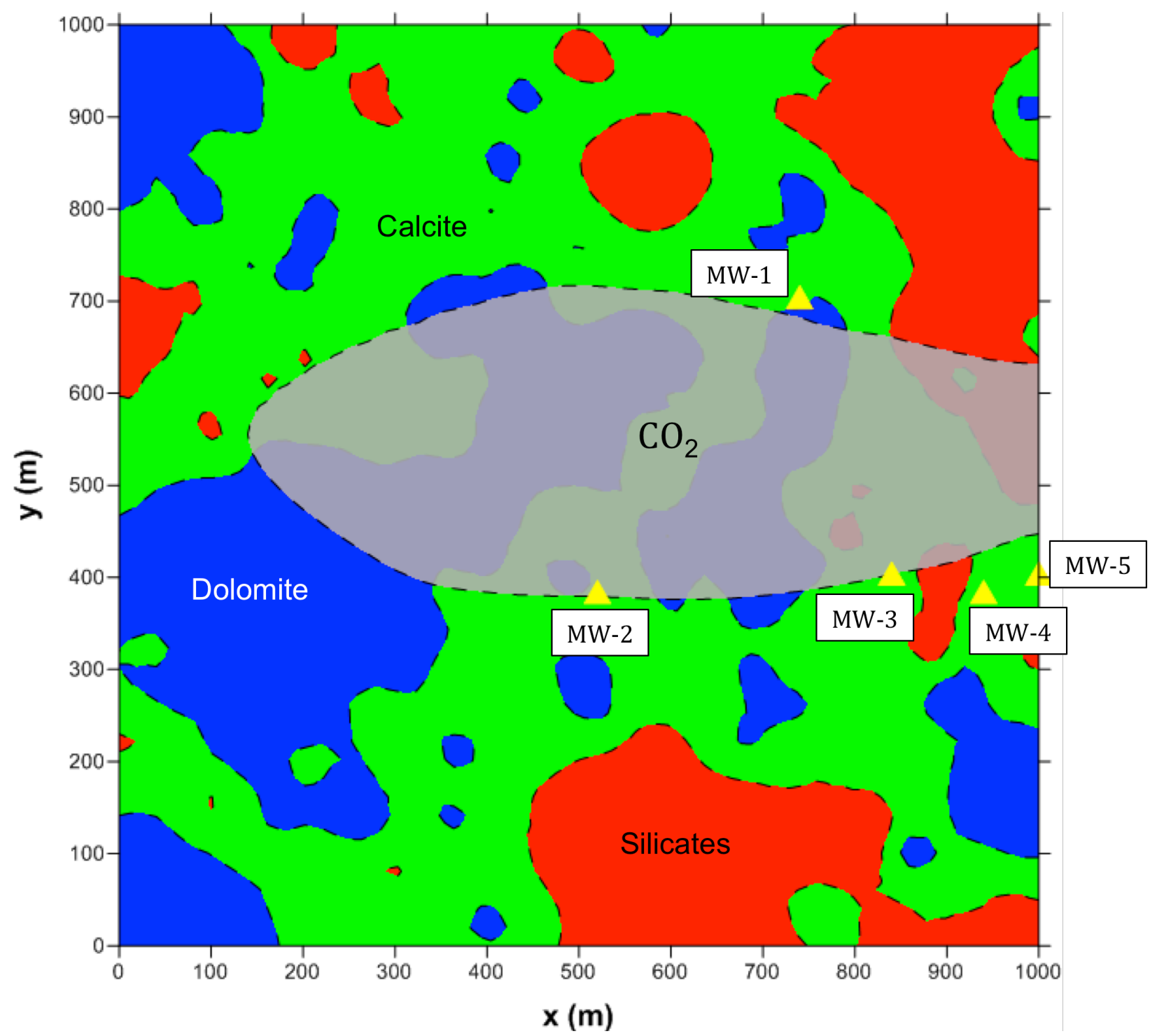

Figure 2.17. Simulated monitoring well locations. 


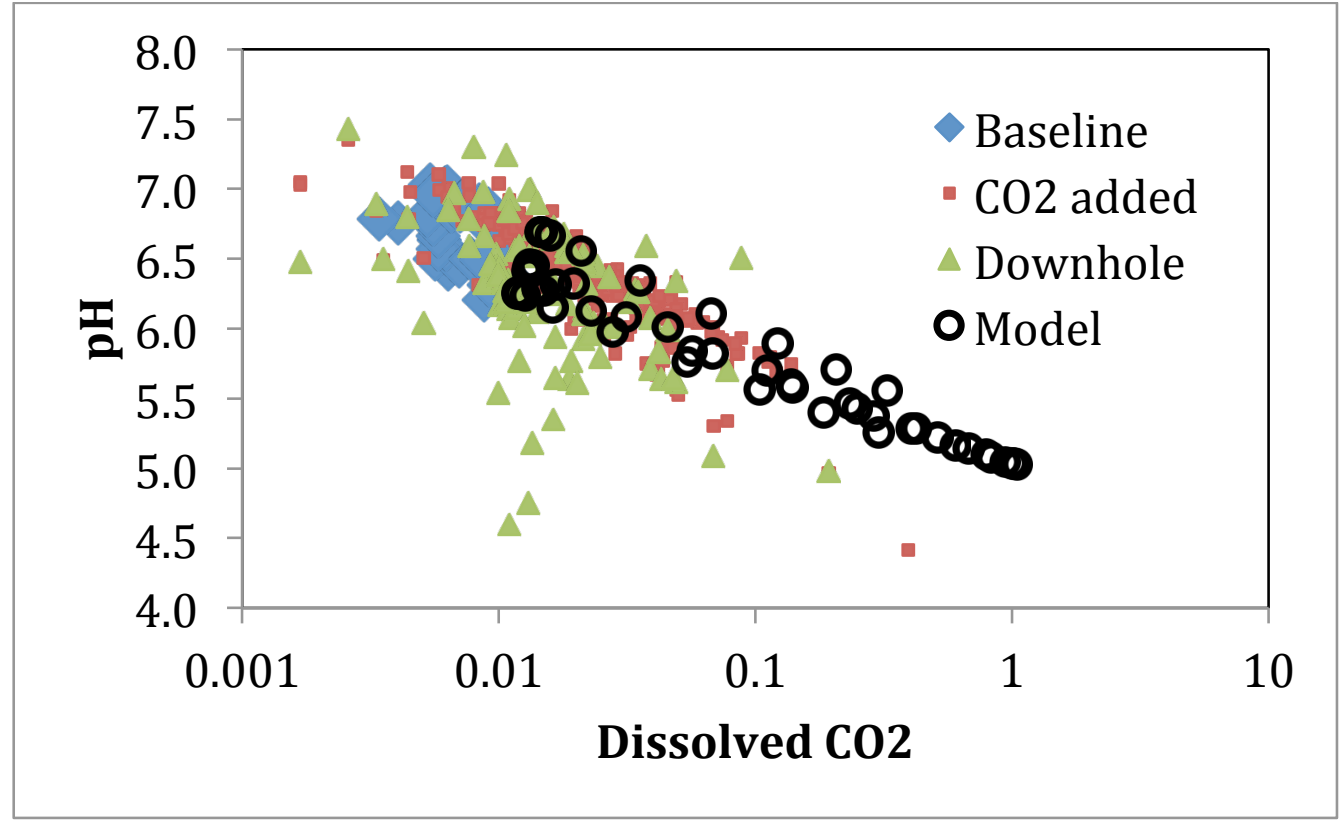

Figure 2.18. Comparison of Baseline, non-baseline $\left(\mathrm{CO}_{2}\right.$ injection period $)$, modeled, and downhole $\mathrm{pH}$ values versus modeled dissolved $\mathrm{CO}_{2}$. Model results correspond to modeled concentrations at monitoring well locations (Figure 2.17) for sampling events occurring every 100 days during simulated $\mathrm{CO}_{2}$ injection. 


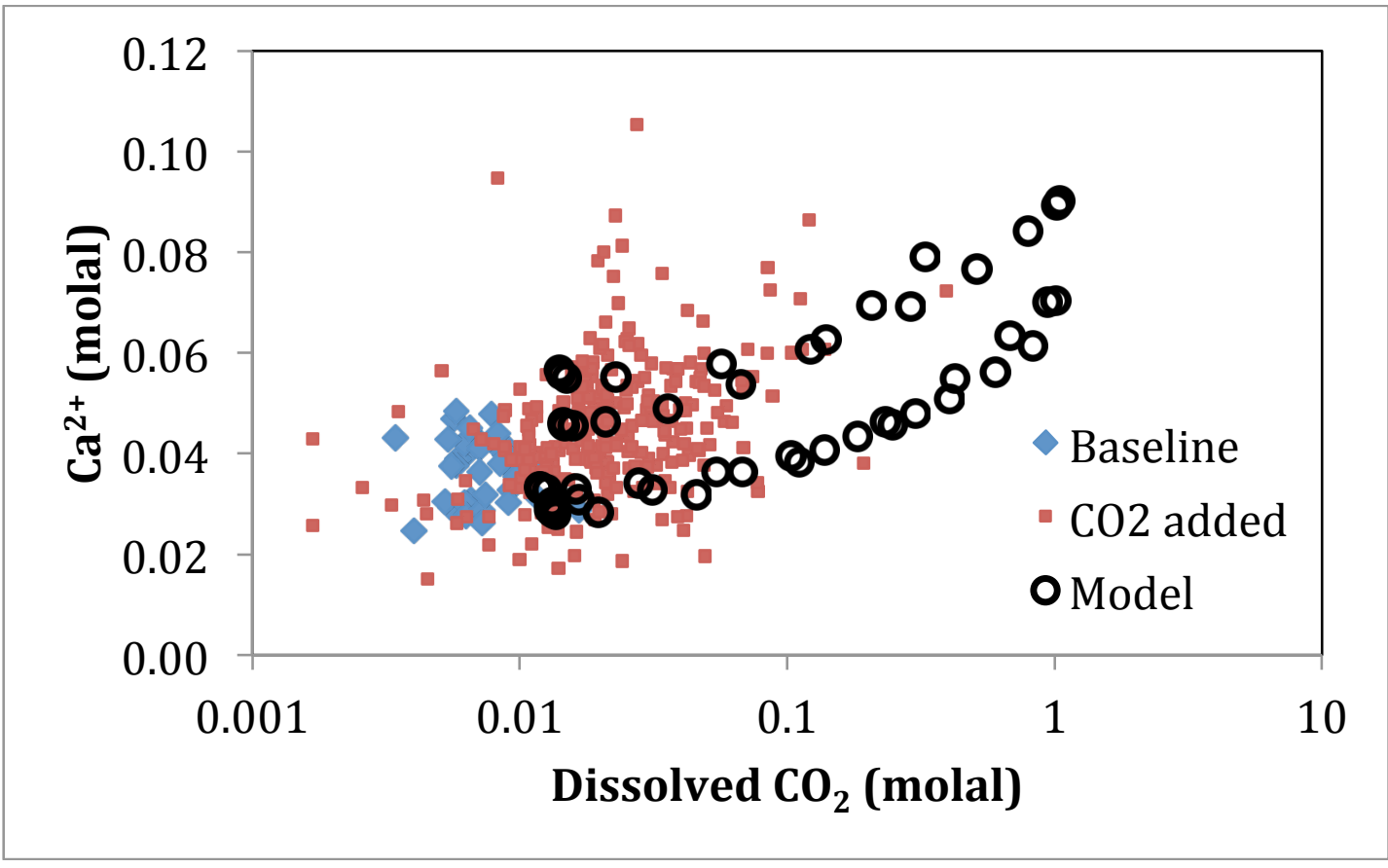

Figure 2.19. Comparison of Baseline, non-baseline $\left(\mathrm{CO}_{2}\right.$ injection period), and modeled $\mathrm{Ca}$ concentration versus modeled dissolved $\mathrm{CO}_{2}$. Model results correspond to modeled concentrations at monitoring well locations (Figure 2.17) for sampling events occurring every 100 days during simulated $\mathrm{CO}_{2}$ injection. 


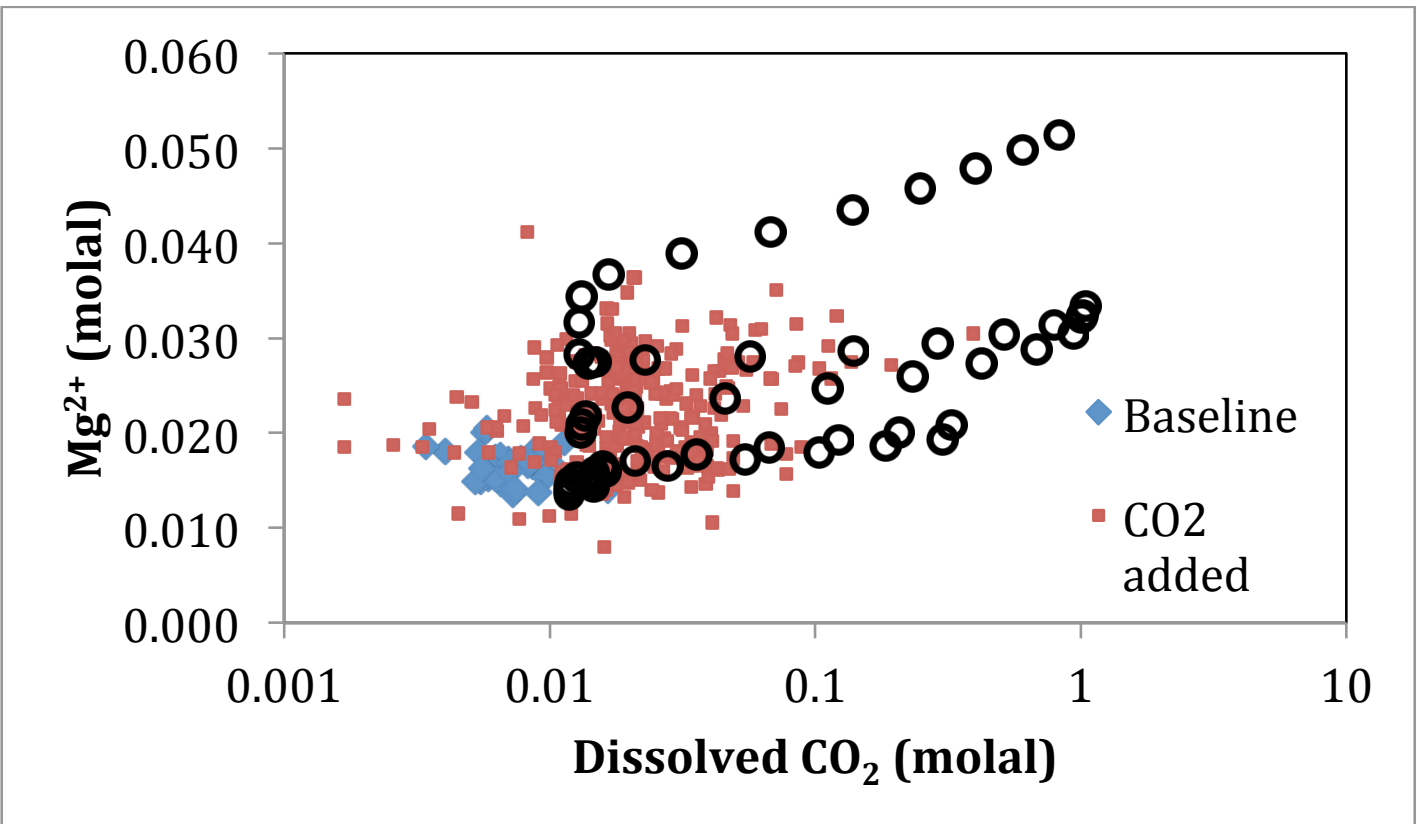

Figure 2.20. Comparison of Baseline, non-baseline $\left(\mathrm{CO}_{2}\right.$ injection period), and modeled $\mathrm{Ca}$ concentration versus modeled dissolved $\mathrm{CO}_{2}$. Model results correspond to modeled concentrations at monitoring well locations (Figure 2.17) for sampling events occurring every 100 days during simulated $\mathrm{CO}_{2}$ injection. 


\section{Inversion of Spatially-Distributed Geochemical Parameters}

The reactive transport model used to posit a synthetic truth scenario for subsequent parameter inversion tacitly assumes that spatial variability in mineral reaction rate constant for a specific mineral can be approximated by variability in the value of the log saturation index or, alternatively, the equilibrium constant for that mineral, provided that the reaction is relatively rapid. However, inversion of the field-scale geochemistry problem will entail estimation of likely reaction rates. As such, extending the equilibrium model described above to encompass reaction kinetics is an important step in developing the inversion algorithm.

As a simple illustration as to how this will be accomplished, we constructed a onedimensional reactive transport model based on many of the same brine chemistry assumptions described above. We assumed that three phases- calcite, (disordered) dolomite, and albite - exist along the length of the column. Each phase dissolves (and calcite also precipitates) according to a lumped reaction rate (moles of mineral mass per second per unit volume of reservoir) in response to its thermodynamic saturation state. The distributions of the mineral phases as well as the associated reaction rates are assumed to be randomly distributed. The objective of the modeling was to run one case as a synthetic truth and then run a number of subsequent simulations, with different random distributions of mineralogy and reaction rates, to test the efficacy of the likelihood function in quantifying good or poor matches to the synthetic truth (and hence provide a criterion for acceptance or rejection of a trial realization). The likelihood function for a particular geochemical parameter is defined by:

$$
L(\underline{x})=k \exp \left(-\frac{1}{N} \sum_{i=1}^{N} \frac{\left.\left|d(\underline{x})_{\text {pred }, i}-d_{0, i}\right|^{n}\right)}{\sigma_{i}^{n}}\right.
$$

where $L(x)$ is a measure of the degree of fit between the model predictions, assuming model $x$, and the observed data, $k$ a normalizing constant, $N$ the number of data points, is $d(\underline{x})_{\text {pred, }, i}$ is the predicted data for a given model $\underline{x}$, is $d_{0, i}$ the vector of observed measurements, $\sigma_{i}$ the estimated data uncertainty, and $n \geq 1$.

The model was based on the one-dimensional reactive transport modeling capability of PHREEQC and assumed that a $\mathrm{CO}_{2}$-enriched Baseline brine composition entered the column from one end, reacted with the minerals, and exited at the opposite end. Total transport time through the 10-cell column was 200 days. The likelihood function (Eq.-1) was based on comparing modeled concentrations of $\mathrm{Ca}$ and $\mathrm{Mg}$ in each realization with the synthetic truth case, assuming $\mathrm{n}=2$ and $\sigma=0.005$ for both cations. The individual likelihood functions for $\mathrm{Ca}$ and $\mathrm{Mg}$ were weighted equally and added together. Among a 
set of 10 random realizations for the distributions of calcite, disordered dolomite, and albite dissolution rates, results for the best match and the worst match to the synthetic truth are shown on Figures 2.21 and 2.22, respectively. The best match among the 10 to the synthetic truth (labeled "Baseline") plotted on Figure 2.22 exhibits a marked correlation between the locations along the column where the rate of dolomite dissolution is relatively high (i.e., locations where dolomite is abundant and/or is characterized by a high specific surface area). For the full inversion, the inversion approach entails:

A full three-dimensional portion of the reservoir system, with a permeability structure based on the seismic inversion;

A larger set of mineralogy (mineral dissolution rate) distributions, generated via the stochastic engine;

The capability of using the likelihood function as a means of selecting specific subsequent realizations, based on the performance of past realizations.

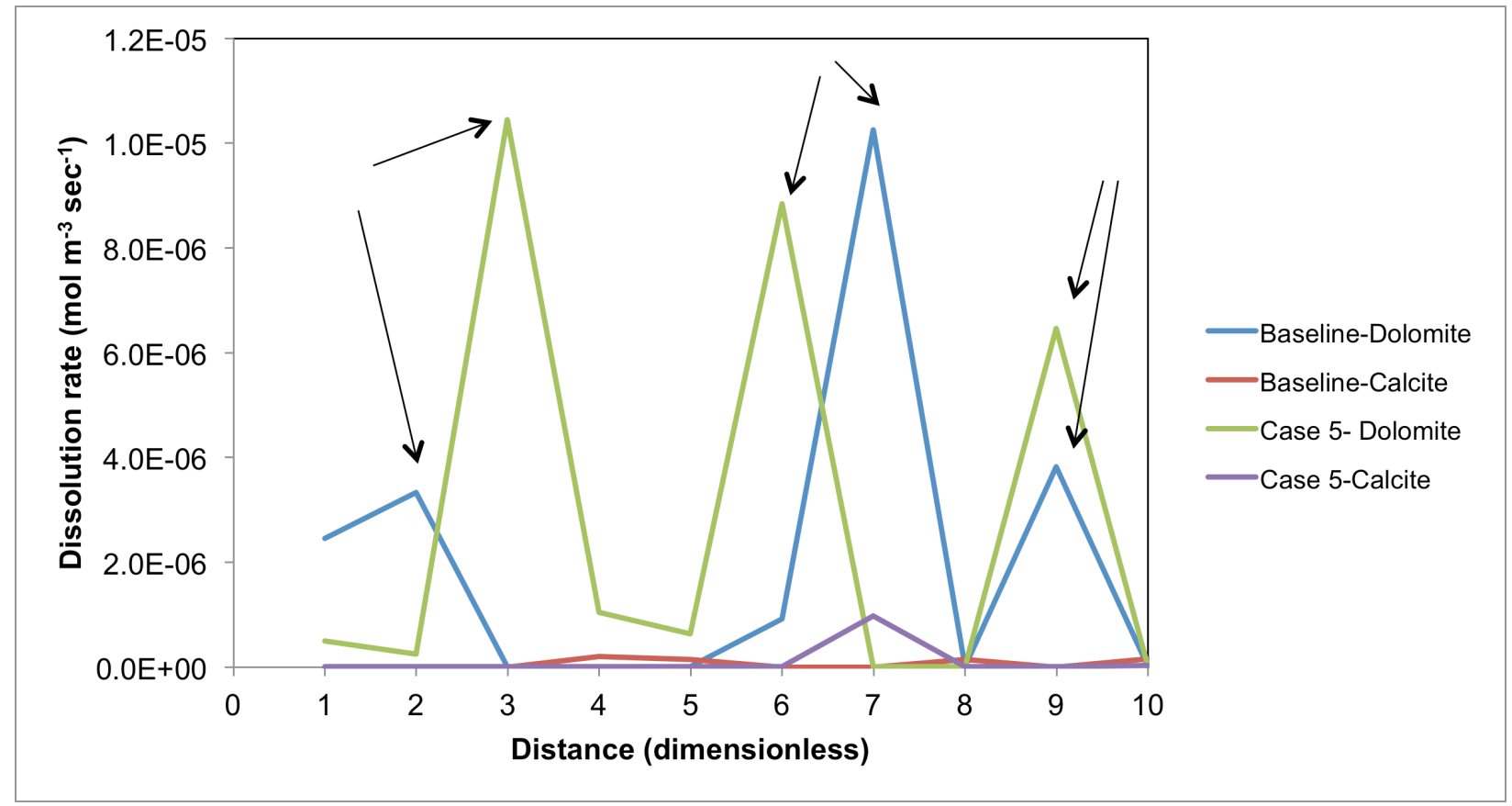

Figure 2.21. Example of a good match between a realization and the synthetic truth (note alignment of dolomite peaks). Likelihood function $=1.42$. 


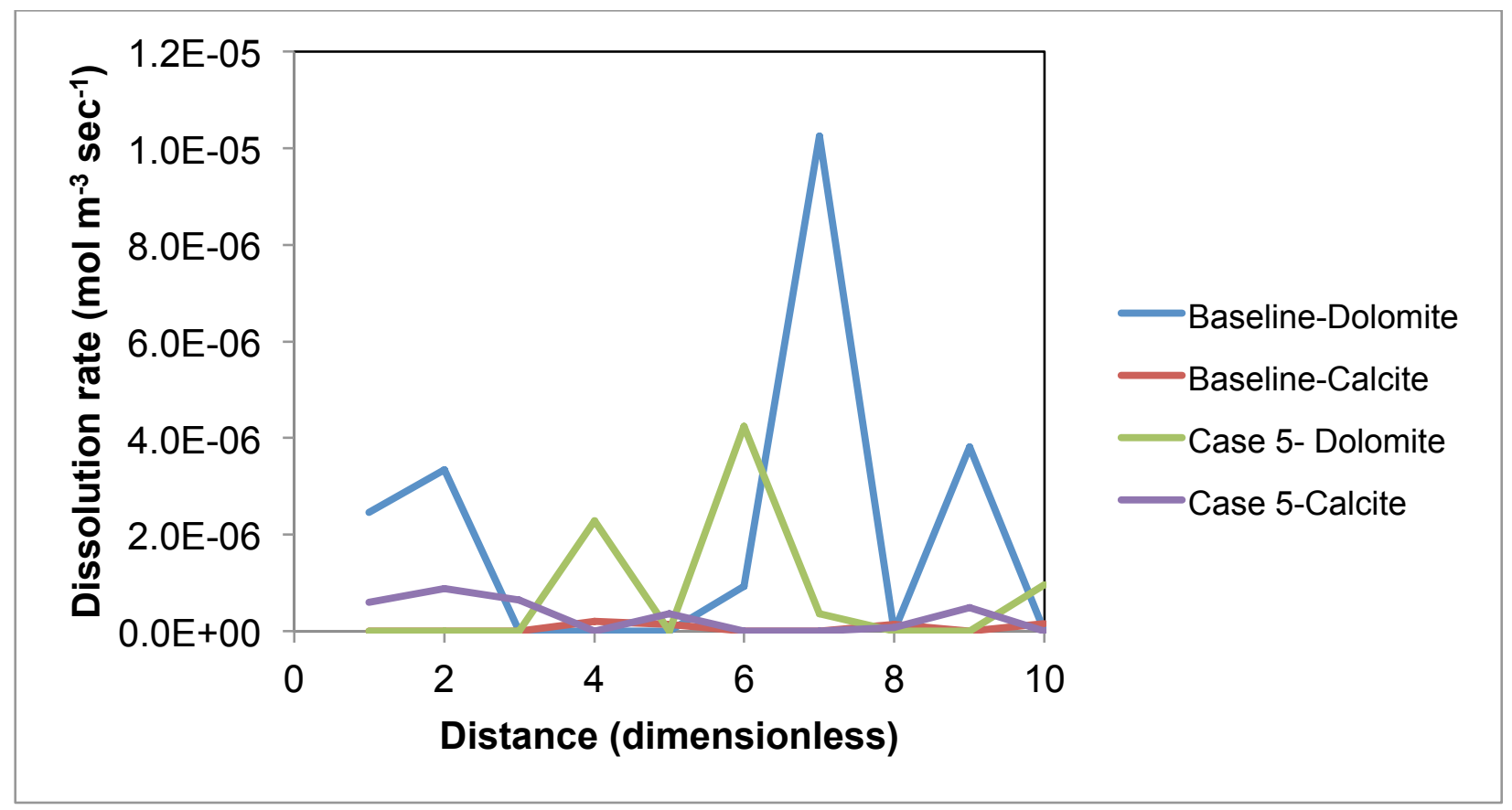

Figure 2.22. Example of a poor match between a realization and the synthetic truth. Likelihood function $=0.09$.

\section{Chapter 3: Geostatistical Analysis of Vuggy Flow Unit Architecture using TProGS}

\section{Introduction}

TProGS is a set of geostatistical analysis software tools that has been recently been added to our stochastic inversion algorithm. These tools are used to analyze the spatial variability of the various facies and to generate reservoir realizations that are constrained by geological data and knowledge of the geological environment. TSIM, one of the TProGS tools, produces reservoir realizations that honor: lithology picks at each well, transition probabilities, length and thickness tendencies, and knowledge of the facies architecture. The model input required by TSIM is developed by a geostatistical analysis of reservoir data. This chapter describes the geostatistical analysis that supports the application of TSIM to the Midale reservoir in pattern 16, phase 1A area.

Heterogeneity of porosity and permeability in the Midale "Vuggy" intervals, particularly within and between the "shoal" and "intershoal" facies, are known to strongly impact the dynamics of enhanced oil recovery by water and $\mathrm{CO}_{2}$ injection into the Weyburn Field 
(Figure 3.1). The Midale "Marly" and "Vuggy" intervals are subdivided into "flow units" for reservoir modeling (Burrowes, 2006). In the vicinity of "Pattern 16" of the Phase 1A study area, the Marly interval is relatively lower in permeability and more homogeneous compared to the Vuggy interval (PTRC, 2004; Whitaker, 2004). Within the Vuggy interval, intershoal facies are characterized by extreme heterogeneity and higher permeability in contrast to the more homogeneous and lower matrix permeability of intershoal facies (Burrowes, 2006). Heterogeneity in the Vuggy interval is expected to cause the greatest impact on flow dynamics within the Midale Formation. Thus, our geostatistical analysis will concentrate on the spatial variability within the Vuggy unit.

This study evaluates spatial variability of Vuggy flow units using transition probabilitybased geostatistical analysis (Carle and Fogg, 1996) and the TProGS software package. Seven Vuggy flow units divide the intershoal facies into two flow units (V1 and V2) and the shoal facies into five flow units (V3, V4, V5, V6, and V7). In this study, existing databases on core rock properties (E. Nickel, 2009, written communication) and flow units (G. Burrowes, 2009, written communication) are merged to evaluate two main questions for stochastic model development:

What are the relative impacts of matrix and fracture porosity and permeability on flow dynamics within the different Vuggy flow units?

What is the uncertainty in the three-dimensional (3-D) flow unit architecture?

Understanding of the relative roles of matrix and fracture porosity and permeability is necessary to define the relevant parameter space for stochastic flow inversion. For example, if both matrix and fracture properties significantly affect flow dynamics, a dualcontinuum computational mesh may be needed to address fracture-matrix interactions, as echoed by PTRC (2004, p. 7):

"Due to the fractured nature of the carbonate reservoir in the Weyburn Unit, some consideration should be given to the application of dual-porosity models."

However, the increased parameter space and computational burden of a dual-continuum (or dual porosity) model must be weighed into effective design of stochastic flow parameter inversion. Alternatively, a single-continuum mesh could address an inversion parameter space more efficiently by focusing on the dominant flow mechanism - either fracture or matrix depending on the rock properties.

The 3-D flow unit architecture is constrained only at borehole locations and, therefore, is uncertain in between boreholes. Depending on the degree of spatial variability of the geometry of the flow units, the uncertainty of 3-D flow unit architecture may or may not be a major factor in stochastic model development for flow evaluation. This study uses geostatistical methods to assess the spatial variability of the 3-D flow unit architecture in the vicinity of Pattern 1 . This assessment can be used to determine the necessity of including variability of flow unit architecture into stochastic flow inversion. 


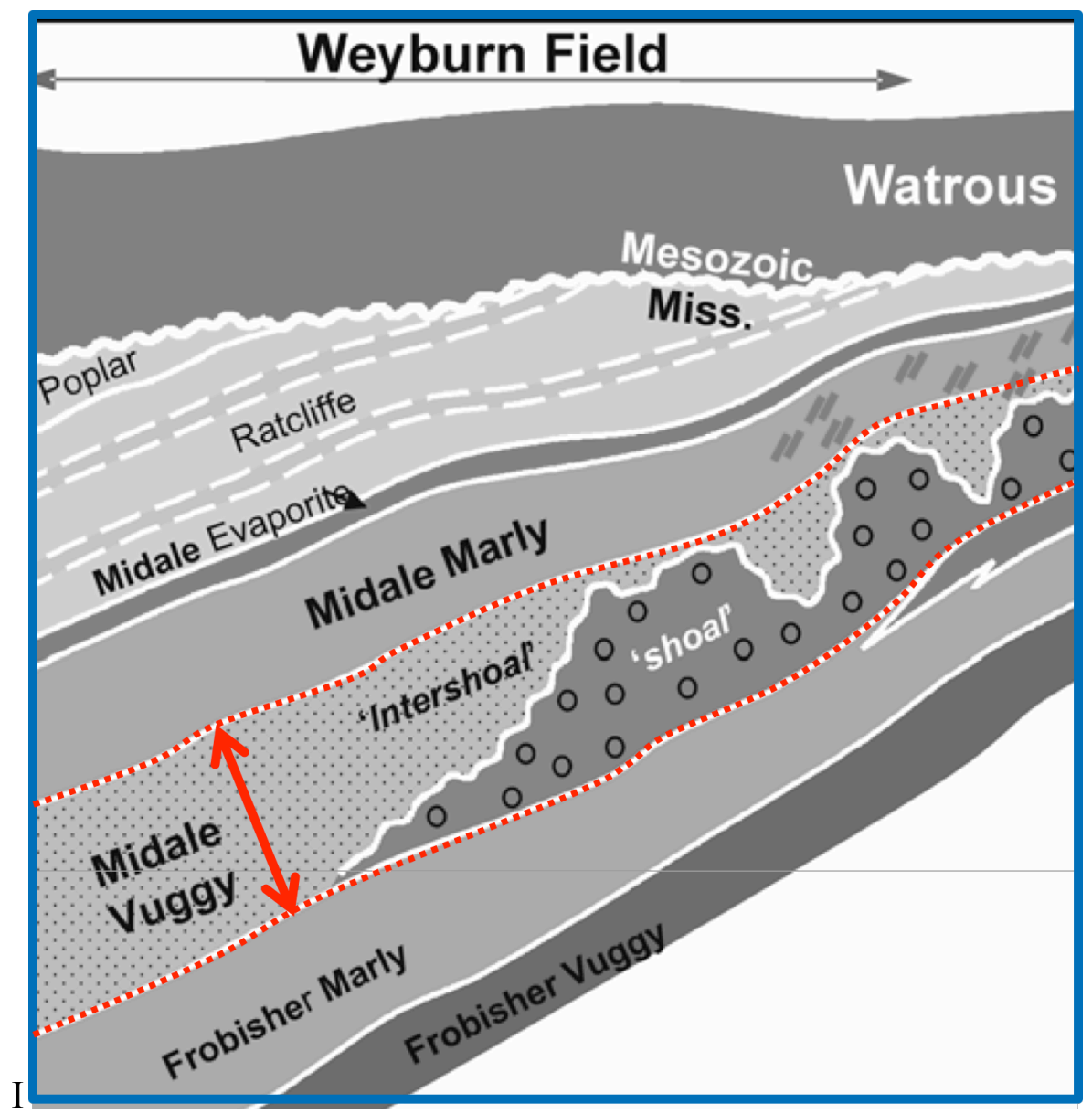

Figure 3.1. Schematic cross-section showing position of Midale Formation, the Midale Marly and Vuggy intervals, and the Vuggy shoal and intershoal facies within the range of the Weyburn Field (modified from Burrowes, 2006).

Data

The data used in this study consist of two separate borehole data sets, one defining locations of flow units and another containing rock properties of core.

\section{Vuggy Flow Units}

A database provided by Burrowes (written communication, 2009) contains borehole identifications, coordinates, and depths to top of formations and flow units. These data are used to measure and model transition probabilities for quantification of 3-D spatial variability of seven flow units identified in the Vuggy interval. Additionally, the depthto-top information is used categorize core porosity and permeability data by flow unit.

\section{Matrix Porosity and Permeability}

A core database provided by E. Nickel (written communication, 2009) contains well identifications, depths, and rock property data including porosity and permeability. Common well identifications and depth ranges were used to extract porosity and permeability data specific to the seven Vuggy flow units named as V1 through V7. During data processing, it was determined that the V1 and V7 flow units are thin, rarely present, and always located on the upper and lower edges of the Vuggy interval and, thus, 
do not substantially contribute to flow within the Vuggy interval. For simplicity, the V1 and V7 flow units are excluded from the geostatistical analysis of flow unit spatial variability. Tables 1 and 2 summarize statistics of V2 through V6 Vuggy flow unit porosity and permeability as determined from the combined core and flow unit databases. Mean porosity in the Vuggy flow units varies between 0.09 and 0.12 , while median porosity tends to be slightly lower, varying between 0.08 and 0.11 . The standard deviation is 0.05 for all flow units except for flow unit V5, with $\mathrm{s}=0.08$ and a much lower number of data. The data indicate similar matrix porosity distributions for all Vuggy flow units, similar to the histogram of matrix porosity data shown for flow unit V3 (Figure 3.2).

Table 1. Vuggy flow unit porosity statistics obtained from the core and flow unit databases.

$\begin{array}{lllll}\text { Unit } & \begin{array}{l}\text { Porosity } \\ \text { \#Data }\end{array} & \text { Mean } & \text { Median } & \text { Std Dev } \\ \text { V2 } & 5780 & 0.12 & 0.11 & 0.05 \\ \text { V3 } & 1012 & 0.09 & 0.08 & 0.05 \\ \text { V4 } & 2632 & 0.11 & 0.10 & 0.05 \\ \text { V5 } & 136 & 0.12 & 0.10 & 0.08 \\ \text { V6 } & 2559 & 0.09 & 0.09 & 0.05\end{array}$

Our evaluation of permeability distributions uses the most prevalent "K-max" data in the core database. Permeability data were evaluated on a $\log 10$ scale considering the data were distributed log-normal and that a geometric mean is representative of effective permeability. Mean $\log 10$ permeability in millidarcies $(\mathrm{mD})$ varies from -0.41 to 0.04 , which equates to 0.47 to $1.09 \mathrm{mD}$. Median $\log 10$ permeability ranges from -0.70 to -0.06 , which equates to 0.20 to $0.87 \mathrm{mD}$.

The permeability data histograms are log-normal within each flow unit, with exception of the lower values of permeability that cluster at $0.1 \mathrm{mD}$ as a result of limitation of data resolution to $0.1 \mathrm{mD}$. Clustering of permeability data at $0.1 \mathrm{mD}$ is clearly evident in the histogram of permeability data for flow unit V3 (Figure 3.3). The limitation of permeability data resolution $0.1 \mathrm{mD}$ tends to raise mean values relative to the median, which would otherwise be equal in a normal distribution. The median values, therefore, are likely better estimates of the geometric mean, because the median value is not affected by clustering of low permeability data at $0.1 \mathrm{mD}$.

The Vuggy interval matrix permeability range of 0.20 to $0.87 \mathrm{mD}$ is far less than typical estimates of 10 to $30 \mathrm{mD}$ for effective permeability in the Vuggy interval (PTRC, 2004). Given the known presence of fractures in the Midale Vuggy interval, fracture networks must dominate permeability and flow dynamics within the Vuggy interval. Fracture permeability spatial variability in the Vuggy interval may be compartmentalized within Vuggy flow units, particularly shoal flow units in which fractures are more common (Whitaker et al., 2006). Therefore, characterization of fracture flow related heterogeneity may remain dependent on spatial variability of flow units, which can be assessed by geostatistical methods. 
Table 2. Vuggy flow unit permeability statistics obtained from the core and flow unit databases.

\begin{tabular}{|c|c|c|c|c|}
\hline \multirow[t]{2}{*}{ Unit } & \multicolumn{4}{|c|}{$\log 10[$ Permeability $(\mathrm{mD})]]$} \\
\hline & \#Data & Mean & Median & Std Dev \\
\hline $\mathrm{V} 2$ & 4499 & $0.04(1.09)$ & $\begin{array}{l}-0.06 \\
(0.87)\end{array}$ & 0.99 \\
\hline V3 & 993 & $\begin{array}{l}-0.41 \\
(0.39)\end{array}$ & $\begin{array}{l}-0.70 \\
(0.20)\end{array}$ & 0.89 \\
\hline V4 & 2341 & $\begin{array}{l}-0.03 \\
(0.93)\end{array}$ & $\begin{array}{l}-0.11 \\
(0.78)\end{array}$ & 0.94 \\
\hline V5 & 115 & $\begin{array}{l}-0.12 \\
(0.76)\end{array}$ & $\begin{array}{l}-0.22 \\
(0.60)\end{array}$ & 0.88 \\
\hline V6 & 2417 & $\begin{array}{l}-0.33 \\
(0.47)\end{array}$ & $\begin{array}{l}-0.48 \\
(0.33)\end{array}$ & 0.81 \\
\hline
\end{tabular}

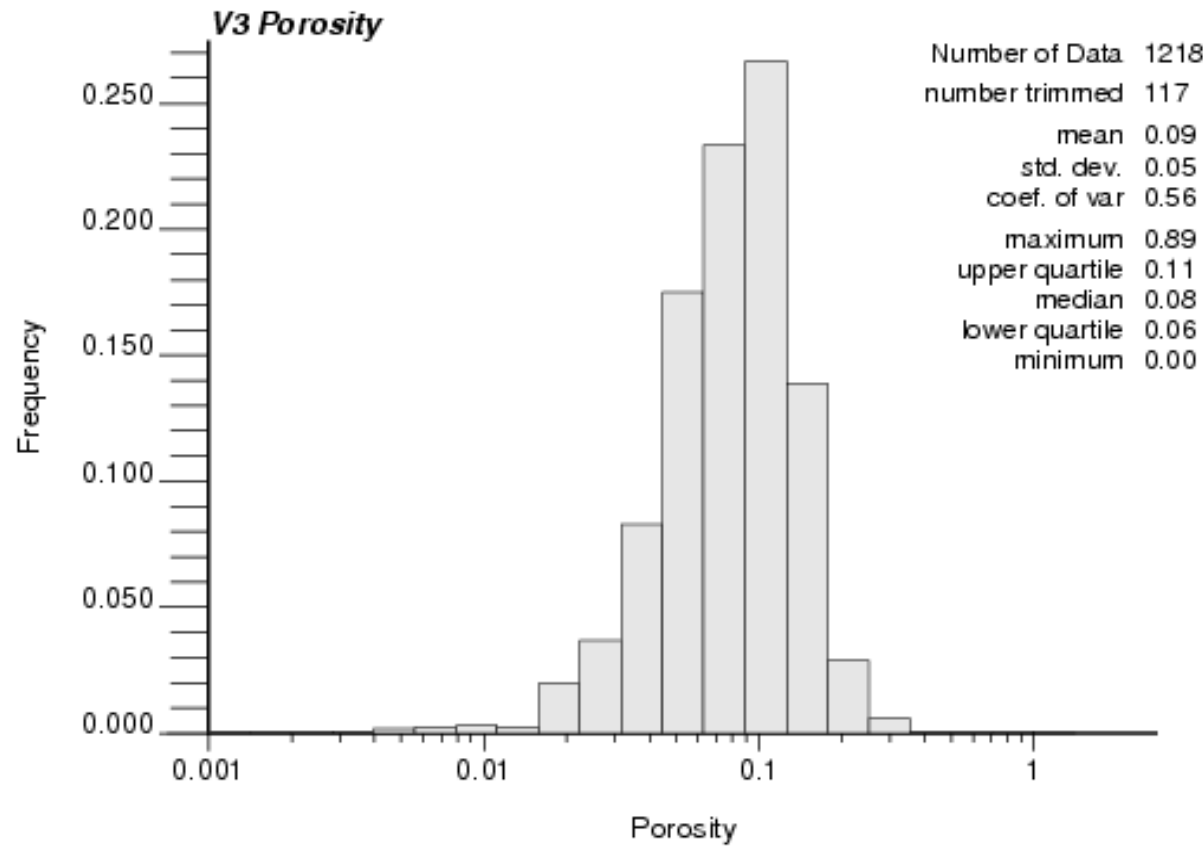

Figure 3.2. Histogram of porosity data for Vuggy flow unit V3 plotted on a log scale. 


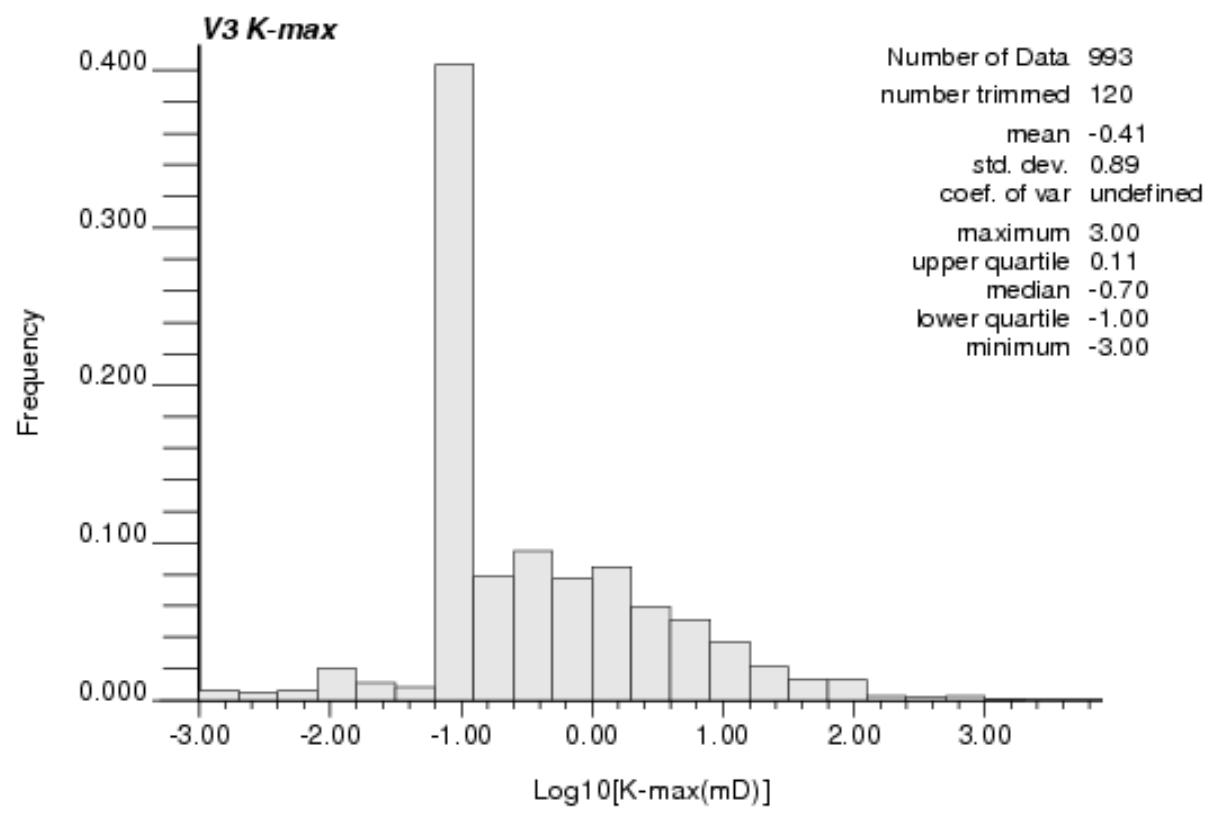

Figure 3.3. Histogram of permeability (K-max) data for Vuggy flow unit V3 plotted on a $\log$ scale.

\section{Fracture Properties}

Quantitative data on fracture properties for the Vuggy interval are not available. Fracture continuity is known to be major in the NE-SW direction (PTRC, 2004). Bogatkov and Babadagli (2008) estimate mean fracture lengths, spacing, and aperature for main and secondary fracture networks within flow units. Such information on fracture properties could be incorporated as prior information for stochastic flow inversion.

However, there is ongoing controversy over fracture characteristics, as exemplified by opposing views of the relative degrees of fracturing within the Midale Marly interval and Vuggy Shoal and Vuggy Intershoal facies:

"Note that fractures are most common in the shoal deposits of the Midale Vuggy" (PTRC, 2004, p. 47)

"It is clear that the Intershoal Vuggy is the most fractured of the formation, followed by the Marly, and finally the Shoal Vuggy" (PTRC, 2004, p. 234)

Moreover, fracture permeability characterization is complicated by the injection process as pressure changes within the reservoirs may open and close fracture systems (PTRC, 2004, p. 83).

\section{Analysis of Spatial Variability of Vuggy Flow Units}

In this study, spatial variability of thickness and lateral continuity of Vuggy flow units is quantitatively evaluated using geostatistical methods. The random variables are indicators for the presence or absence of Vuggy flow unit at a location $\mathbf{x}$

$I_{k}(\mathbf{x})=\left\{\begin{array}{l}1 \text { if flow unit } k \text { is present at } \mathbf{x} \\ 0 \text { if flow unit } k \text { is not present at } \mathbf{x}\end{array} \quad k=V 1, V 2, \ldots, V 7\right.$

Spatial variability can be measured by the transition probability as a function a separation vector $(\mathbf{h})$

$t_{k l}(\mathbf{h})=\operatorname{Pr}\{$ flow unit $l$ occurs at location $\mathbf{x}+\mathbf{h}$ given flow unit $k$ occurs at $\mathbf{x}\}$ 
Other geostatistical measures of spatial variability can be used, such as indicator crosscovariance or indicator variogram, but the transition probability carries as much or more statistical information including asymmetrical juxtapositional relationships such as fining upward cycles (Carle and Fogg, 1996).

\section{Vertical Spatial Variability}

Vertical spatial variability is evaluated from transition probabilities between pairs of data spaced of different upward separation distances or "vertical lags." The calculated transition probabilities for Vuggy flow units V2 to V6 are shown by the circled dots in Figure 3.4. The strictly upward layered sequence of $\mathrm{V} 6>\mathrm{V} 5>\mathrm{V} 4>\mathrm{V} 3>\mathrm{V} 2$ yields a strongly asymmetric transition probability matrix, with entirely zero values in the lower left off-diagonal. The diagonal entries represent the auto-transitions. Greater mean thickness is indicated by less steepness in the slope of the diagonal transition probability at zero lag. The vertical transition probability data suggest mean flow unit thicknesses of infinity (V2), $1.08 \mathrm{~m}(\mathrm{~V} 3), 3.01 \mathrm{~m}(\mathrm{~V} 4), 0.43 \mathrm{~m}$ (V5), and $3.76 \mathrm{~m}(\mathrm{~V} 6)$. The zero slope at $\mathrm{t}_{\mathrm{V} 2-\mathrm{V} 2}(0)$ is caused by assumed upper termination of the Vuggy interval at the top of the V2 flow unit. The inferred mean thickness of infinity for V2 is an artifact of the analysis because data for calculation of the $\mathrm{V} 2$ vertical auto-transition probability, $\mathrm{t}_{\mathrm{V} 2}$ $\mathrm{V}_{2}\left(h_{\mathrm{z}}\right)$, are always contained within the V2 flow unit, while geostatistical measures of spatial variability assume, in theory, infinite boundaries.

The solid black line in Figure 3.4 represents a Markov chain model fit to data at the first non-zero lag of $0.5 \mathrm{~m}$. A Markov chain is a simple stochastic model represented by a matrix exponential function which has found widespread applicability in facies architecture modeling (Carle et al., 1998; Weissmann et al., 1999). If spatial variability is Markovian, transition probability measurements will tend to fall on the solid line. While the Markov chain successfully implements asymmetry evident in the measured transition probabilities, the Markov chain does not closely fit measured Vuggy flow unit vertical transition probabilities at each lag. The differences between measured and Markov chain transition probabilities indicate a more uniformly layered carbonate system compared to more Markovian spatial variability pattern typical of alluvial or fluvial deposits. 


\section{Vuggy Units V2-V6 Vertical Direction}

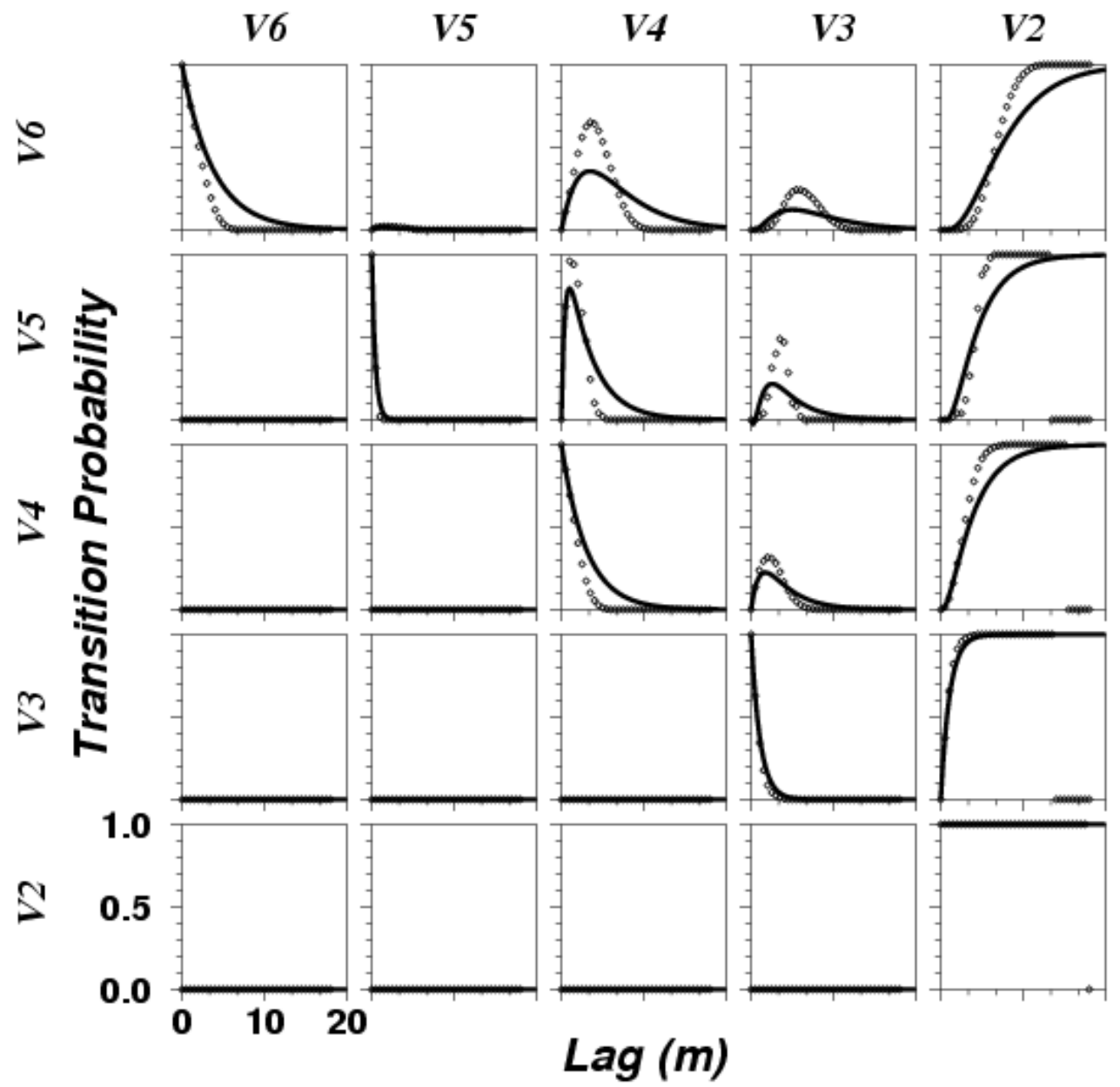

Figure 3.4. Vertical transition probability matrix for V2-V6 Vuggy flow units, with dots representing measured data and solid line representing a Markov chain model fit to data at first non-zero lag $(0.5 \mathrm{~m})$.

\section{Lateral Spatial Variability}

Lateral spatial variability in geologic data is generally more difficult to measure than vertical spatial variability because of data sampling patterns (typically along vertical boreholes), variable dip angles (structure), and inaccurate vertical control. Inevitable lateral sparseness in subsurface data spacing leads to greater error in measurement of spatial variability in lateral directions compared to vertical. To minimize effects of dip angles, the vertical scale unit for the data was converted to depth below the top of the Vuggy interval. In this manner, structural controls causing variable dip of the Vuggy interval are largely removed so that lateral correlation can be evaluated with correction for dip structure. Without a structure correction, lateral spatial correlation of Vuggy flow units will be underestimated. In practice, lateral spatial correlation is very difficult to quantitatively measure without many closely-spaced boreholes. 
At Weyburn, however, the numerous boreholes, high lateral continuity (compared to alluvial or fluvial systems), and consistent geologic interpretation are unusually conducive to quantitative evaluation of lateral spatial variability of the Vuggy flow units. The lateral-direction transition probabilities shown in Figure 3.5 were calculated assuming isotropy (radial symmetry) in the lateral plane. The lateral isotropy assumption reduces measurement error by accumulating more data pairs for calculation of transition probability at the specified lags. Other evaluations of lateral transition probabilities were made assuming preferential directions in the northwest or northeast directions, resulting in little difference in measured transition probabilities.

The data are sufficient to detect lateral correlation scales and juxtapositional tendencies for the Vuggy flow units. Mean lengths in the lateral direction are $1537 \mathrm{~m}$ (V2), $199 \mathrm{~m}$ (V3), $317 \mathrm{~m}$ (V4), $94 \mathrm{~m}$ (V5), and $1034 \mathrm{~m}$ (V6). The measured lateral transition probabilities indicate tendency of flow units to juxtapose laterally to the vertically adjacent flow units (e.g. V3 tends to be justaposed laterally adjacent to V2 or V4), except for lateral transition to V5 which is of very low proportions.

The flow unit architecture is dominated by flow units V2, V3, V4, and V6. Two Markov chain models were constructed: (1) from data at the first non-zero lag of $200 \mathrm{~m}$ (dashed lines) and(2) typical practice of fitting a model (solid lines) to transition probabilities of all but one category (here, fitting to V3, V4, V5, and V6 and prescribing V2 as "background") and prescribing proportions indicated by the data. In both cases, the lateral transition probability models do not fit the data at larger lags, suggesting that a stationary Markov model with or without assuming fixed proportions cannot fit the transition probability at all lags. This is not surprising because of the monotonically layered nature of the flow unit architecture. 


\section{Vuggy Units V2-V6 \\ Lateral Direction}

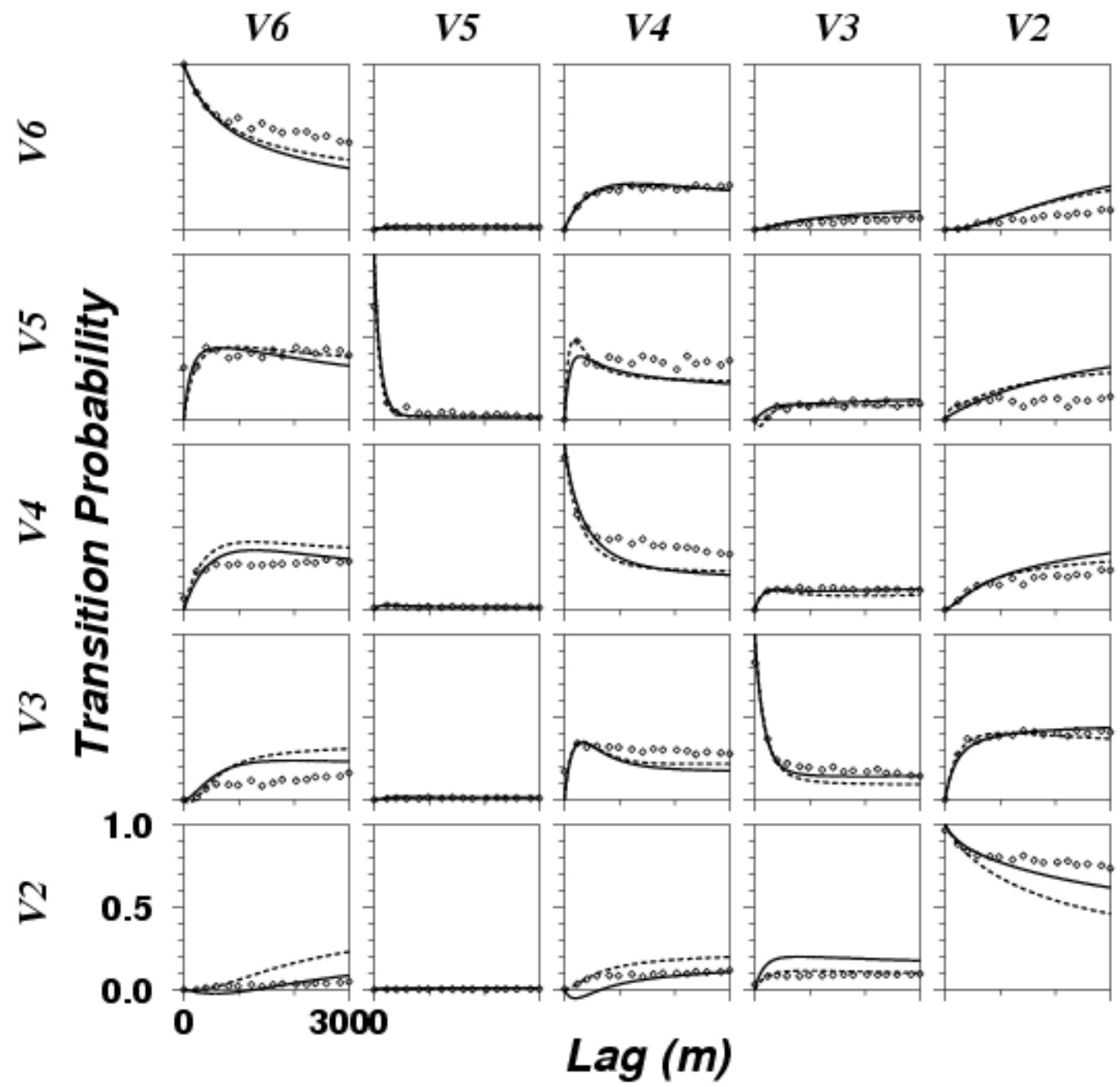

Figure 3.5. Lateral transition probability matrix for V2-V6 Vuggy flow units, with dots representing measured data, dashed line representing a Markov chain model fit to data at first non-zero lag $(200 \mathrm{~m})$, and solid line another Markov chain model fit to V3-V6 transition probability measurements.

\section{Geostatistical Simulation of Vuggy Flow Unit Architecture}

Development of a stochastic model such as a Markov chain enables geostatistical simulation of multiple "realizations" or equally probable three-dimensional distributions of the categorical variables (e.g., flow units) that honor both fixed data (e.g., flow unit interpretations at boreholes) and the bivariate spatial statistics (e.g. transition probabilities). Here we use the TSIM code (Carle, 1996) to generate realizations of Vuggy flow unit architecture conditioned to borehole flow unit data near Pattern 1. The1-D Markov chain models for the vertical and lateral directions are used to develop a 
3-D Markov chain model for the TSIM simulation algorithm (Carle, 1996; Carle and Fogg, 1997).

Figure 3.6 shows two realizations generated by TSIM conditioned to six boreholes near Pattern 1 with Vuggy flow unit architecture determined by the 3-D Markov chain model derived from borehole flow unit data. The realizations generally preserve the monotonic vertical sequence of V2, V3, V4, and V6 flow units. Lateral continuity is extensive in these two and another eight realizations not shown, indicating that the flow unit architecture near Pattern 1 is consistently layered for the V2, V3, V4, and V6 units. The different realizations have spatially varying flow unit thicknesses, but the main portions of V2, V3, V4, and V6 flow units remain entirely or nearly continuous in the lateral direction. These simulation results suggest that discontinuities in flow units, which might explain preferential flowpaths, are not likely to occur near Pattern 1.

\section{Conclusions and Recommendations}

Conclusions and recommendations from this study include:

(1) Mean matrix porosity is uniform between different flow units in the Vuggy interval, and matrix permeability is low relative to the fracture permeability in the Vuggy interval. (2) With the exception of three minor Vuggy flow units (V1, V5, and V7), the four major Vuggy flow units (V2, V3, V4, and V6) are relatively uniformly layered within the Pattern 1 area and, therefore, the 3-D flow unit architecture is tightly constrained as four continuous layers of flow units V2, V3, V4, and V6.

(3) Given much higher permeability and uncertainty in permeability structure for fracture flow relative to matrix flow, stochastic modeling for flow evaluation in Pattern 1 should focus on fracture property heterogeneity.

(4) Based on this study, a reasonable approach to stochastic flow inversion at Pattern 1 would be to fix matrix properties and geometry for the Marly interval and Vuggy flow units V2, V3, V4, and V6 flow and invert on fracture properties using a dual-continuum mesh. Much challenge remains in characterization of fracture properties in the Midale Formation. 


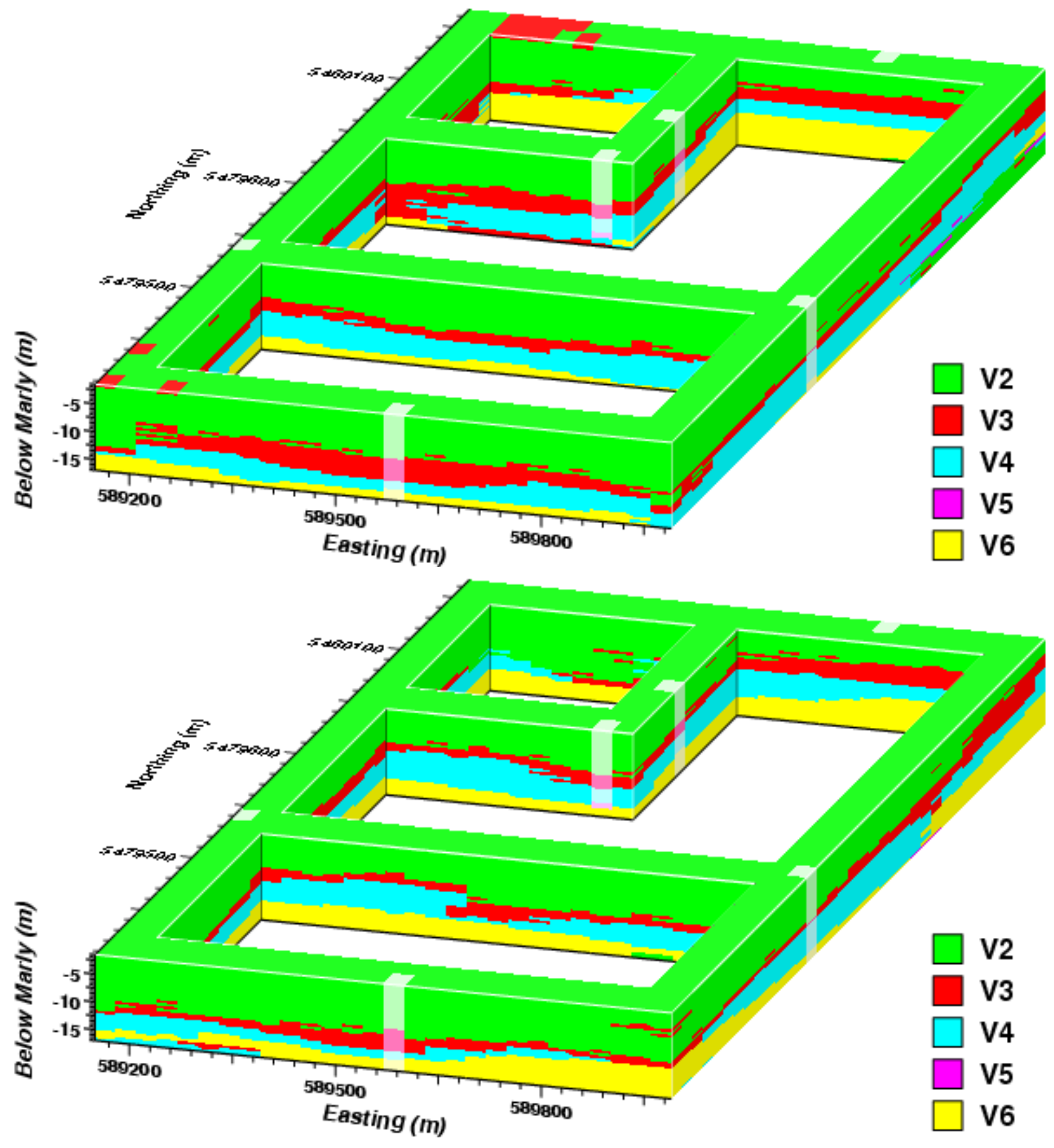

Figure 3.6. Two realizations generated by TSIM conditioned to six boreholes near Pattern 1 with Vuggy flow unit architecture determined by the 3-D Markov chain model derived from borehole flow unit data. 


\section{Acknowledgements}

We are grateful for the funding support provided by the Petroleum Technology Research Center, Saskatchewan, Canada. We are also grateful for the data provided by Barbara Dietiker (Geological Survey of Canada) and Erik Nickel (Saskatchewan Ministry of Energy and Resources).

\section{References}

Bogatkov, D., and Babadagli, T., 2008, Integrated Modeling and Statistical Analysis of 3D Fracture Network of the Midale Field, International Petroleum Technology Conference, IPTC 12165.

Brown, L. 2002, Integration of rock physics and reservoir simulation for the interpretation of time-lapse seismic data at Weyburn Field, Saskatchewan, M. Sc. thesis, Colorado School of Mines, Golden, CO.

Burrowes, G., 2006, Genesis of Mississippian shoal topography, Weyburn Field, Saskatachewan; in E. H. Nickel (ed), Saskatchewan and Northern Plains Oil \& Gas Symposium Core Workshop Volume, Saskatachewan Geological Society Special Publication 20, p. 22-31.

Carle, S. F., 1996, A Transition Probability-Based Approach to Geostatistical Characterization of Hydrostratigraphic Architecture, Ph. D. Dissertation, University of California, Davis.

Carle, S.F. and Fogg, G.E., 1996, Transition Probability-Based Indicator Geostatistics: Mathematical Geology, v28, n4, p453-476.

Carle, S.F. and Fogg, G.E. 1997, Modeling spatial variability with one and multidimensional continuous-lag Markov chains: Mathematical Geology, v. 29, n. 7, p. 891-918

Carle, S.F., Labolle, E.M., Weissmann, G.S., Van Brocklin, D, and Fogg, G.E., 1998, Geostatistical simulation of hydrofacies architecture, a transition probability/Markov approach: in Fraser, GS; Davis, JM, Hydrogeologic Models of Sedimentary Aquifers, Concepts in Hydrogeology and Environmental Geology No. 1, SEPM (Society for Sedimentary Geology) Special Publication, p. 147-170

Emberley, S., I. Hutcheon, M. Shevalier, K. Durocher a, B. Mayer a, W.D. Gunter, and E.H. Perkins, 2005. Monitoring of fluid-rock interaction and $\mathrm{CO}_{2}$ storage through produced fluid sampling at the Weyburn $\mathrm{CO}_{2}$-injection enhanced oil recovery site, Saskatchewan, Canada, Applied Geochemistry, 20, 1131-1157. 
Parkhurst, D.L. and Appelo, C.A.J., 1999. User's Guide to PHREEQC (version 2)--A Computer program for Speciation, Batch-Reaction, One-Dimensional Transport, and Inverse Geochemical Calculations, U.S. Geological Survey Water-Resources Investigations Report 99-4259, $312 \mathrm{p}$.

Parkhurst, D.L., K. L. Kipp, P. Engesgaard, and S. R. Charlton, 2004. PHAST-A Program for Simulating Ground-Water Flow, Solute Transport, and Multicomponent Geochemical Reactions, Techniques and Methods 6-A8, U.S. Geological Survey, 154 p.

PTRC, 2004, IEA CHG Weyburn CO2 Monitoring \& Storage Project Summary Report 2000-2004, M. Wilson and M. Monea, Eds., Petroleum Technical Research Centre, 283 p.

Ramirez, A., Y. Hao, D. White, S. Carle, K. Dyer, X. Yang, W. Mcnab, W. Foxall, and J. Johnson, 2009, Development of a Stochastic Inversion Tool To Optimize Agreement Between The Observed And Predicted Seismic Response To $\mathrm{CO}_{2}$ Injection/Migration in the Weyburn-Midale Project, Lawrence Livermore National Laboratory, LLNL-TR420989, Livermore CA.

Ramirez, A., K. Dyer, D. White, Y. Hao, and X. Yang, 2010, Model verification: synthetic single pattern simulations using seismic reflection data, Lawrence Livermore National Laboratory, LLNL-TR-441596, Livermore CA.

Weissmann, G. S., Carle, S. F., and Fogg, G. E., 1999, Three-dimensional hydrofacies modeling based on soil surveys and transition probability geostatistics: Water Resources Research, v35, n6, p1761-1770.

Whittaker, S.G., 2004: Investigating geological storage of greenhouse gases in southeastern Saskatchewan: The IEA Weyburn CO2 Monitoring and Storage Project; in Summary of Investigations 2004, Volume 1, Saskatchewan Geological Survey, Sask. Industry Resources, Misc. Rep. 2004-4.1, CD-ROM, Paper A-2, 12p. 